\title{
Influence of a white noise at channel inlet on the parallel and wavy convective instabilities of Poiseuille-Rayleigh-Bénard flows
}

\author{
Xavier Nicolas, ${ }^{1, \text { a) }}$ Noussaiba Zoueidi, ${ }^{1, b)}$ and Shihe $\mathrm{Xin}^{2, \mathrm{c})}$ \\ ${ }^{1}$ Université Paris Est, MSME UMR 8208 CNRS, 5 Boulevard Descartes, 77454 Marne la \\ Vallée Cedex 2, France \\ ${ }^{2}$ Université de Lyon, INSA-Lyon, CETHIL, UMR 5008 CNRS, 9 Rue de la Physique, \\ 69621 Villeurbanne, France
}

(Received 11 February 2012; accepted 12 June 2012; published online 9 August 2012)

\begin{abstract}
The present paper concerns Poiseuille-Rayleigh-Bénard mixed convection flows in horizontal rectangular air-filled channels of large spanwise aspect ratio $(\mathrm{W} / \mathrm{H} \geq 10)$ and it focuses on the primary and secondary thermoconvective instabilities made of steady longitudinal and unsteady wavy rolls for $100 \leq \mathrm{Re} \leq 200,3000<\mathrm{Ra}<15$ $000, \operatorname{Pr}=0.7$, and $\mathrm{W} / \mathrm{H}=10$. Time linear stability analysis of longitudinal rolls and 3D nonlinear numerical simulations using a specially tailored finite difference code is performed for this purpose. A bibliographical review, linear stability analysis and 3D numerical simulations allow establishing the full stability diagram for $\operatorname{Re} \leq 300$ and $\mathrm{Ra} \leq 20$ 000. The linear stability analysis indicates that the critical Rayleigh number $\mathrm{Ra} \approx *(\mathrm{Re})$ of the neutral curve between longitudinal and wavy rolls for $\mathrm{W} / \mathrm{H}=10$ is increased at least by a factor of 1.5 in comparison with infinite $\mathrm{W} / \mathrm{H}$. The numerical study shows that the usual definitions of growth lengths for longitudinal rolls are inappropriate and it explains the discrepancies observed on wall Nusselt numbers in the literature between experimental and numerical results for the fully developed longitudinal rolls: Nusselt number decreasing at $\mathrm{Ra}>8000$ is due to spanwise oscillations of thermoconvective rolls that favor a bulk temperature homogenization. Because they are a convective instability, wavy rolls and their space and time development are studied numerically by maintaining at channel inlet, a permanent random excitation: it is designed to cover all the modes and allows detecting the wavy roll modes that are naturally amplified by the flow and those that are damped. Wavy roll patterns are characterized with respect to its three control parameters: Re, the relative distance $\varepsilon$ to the critical Rayleigh number $\mathrm{Ra} \approx *$, and the excitation magnitude $\mathrm{A}_{\mathrm{exc}}$. The growth length of the wavy rolls is shown to correlate with $\varepsilon^{-0.72}$ and $\log \left(\mathrm{A}_{\text {exc }}\right)$. The frequency, wave number, and phase velocity of the most amplified mode, the wall averaged Nusselt number and the spanwise displacements of the wavy rolls are independent of $\mathrm{A}_{\mathrm{exc}}$ in the fully developed zone, but depend a lot on $\varepsilon$ for $\varepsilon<2$ and nearly stabilize for $\varepsilon>2$ (i.e., $\mathrm{Ra}>3 \mathrm{Ra} \approx *$ ). Correlation laws as a function of $\mathrm{Re}, \varepsilon$, and $\mathrm{A}_{\mathrm{exc}}$ are proposed for most of the exploited quantities. Numerical simulations performed are in a good agreement with experimental results on the wavy rolls obtained by Pabiou et al. ["Wavy secondary instability of longitudinal rolls in Rayleigh-Bénard-Poiseuille flows," J. Fluid Mech. 542, 175 (2005)]. Finally, wavy roll characteristics are shown to be potentially interesting to better homogenize the vapor depositions in the horizontal rectangular chemical vapor deposition reactors
\end{abstract}


used to make thin coatings on heated substrates from gaseous components. (C) 2012

American Institute of Physics. [http://dx.doi.org/10.1063/1.4737652]

\section{INTRODUCTION}

Poiseuille-Rayleigh-Bénard (PRB) flows are Rayleigh-Bénard convection with a superimposed Poiseuille flow between two horizontal infinite parallel plates or in a horizontal channel of constant rectangular cross section, heated from below and cooled from above. These mixed convection flows have been intensively studied during the last 30 years because they have both practical and fundamental interests. For an exhaustive bibliographical review of the researches on PRB flows before 2002, one can refer to Ref. 1 . Here and in Sec. II, we only present main papers on the subject and more recent ones.

As far as industrial applications are concerned, PRB flows are representative of gaseous flows in rectangular chemical vapor deposition (CVD) reactors ${ }^{2}$ used to make thin solid films or coatings on flat substrates from gaseous precursors. In these reactors, thermoconvective instabilities of the gaseous flow may condition the mass transfer from the gaseous reactive species towards the substrate and the thickness of the solid films deposited on it. For a recent review on this subject and more particularly on PRB flows in atmospheric pressure CVD reactors, one may refer to Ref. 3. The heat transfer increase associated with different thermoconvective patterns of the PRB configuration has also been investigated in the context of the air cooling of electronic circuit board packages. ${ }^{4}$ In this case, the heating is generally made of several discrete heat sources placed on the bottom and/or top plates of the channel.

From a more fundamental point of view, PRB flows are a very interesting configuration because numerous thermoconvective instabilities can develop and because they can be convective or absolute, ${ }^{5-9}$ depending on the four dimensionless parameters that control the flow: namely, Reynolds, Rayleigh and Prandtl numbers ( $\mathrm{Ra}, \mathrm{Re}, \mathrm{Pr})$, and channel spanwise aspect ratio $(B=\mathrm{W} / \mathrm{H})$. We remind that a basic flow is called "linearly stable" if an infinitesimal and localized perturbation damps both in space and time. It is "absolutely unstable" if this perturbation grows both in space and time, until reaching saturation and a new state. Finally, it is "convectively unstable" if this perturbation grows with time but decreases locally due to its transport by the mean flow. As a consequence, when a basic flow is convectively unstable, a single perturbation does not allow a transition towards a new state but, if this basic flow is permanently excited, this transition is possible. Note that the use and the meaning of "convective (or absolute) instability" and "convectively (or absolutely) unstable" are delicate. The appropriate use is to say that a basic state is convectively (or absolutely) unstable towards a new state and, as a consequence, this new state is a convective (or absolute) instability of the basic state. Thus, for instance, we are going to see that the longitudinal rolls of PRB flows are convectively unstable towards the wavy rolls and the wavy rolls are a convective instability of the longitudinal rolls.

The various thermoconvective instabilities of PRB flows are referred to as transverse $(\perp)$, longitudinal $(/ /)$, mixed transverse and longitudinal (mix), wavy $(\approx)$, oscillating (osc), varicose, irregular, or chaotic thermoconvective rolls. Note that the notations in brackets introduced here are used in the figures to designate the different thermoconvective instabilities. For instance, $\perp$ or $\mathrm{R}_{\perp}$ means transverse rolls, // or $\mathrm{R}_{/ /}$means longitudinal rolls, and $\approx$ or $\mathrm{R} \approx$ means wavy rolls. As the stability analysis of each pattern is disseminated in the literature, an overall stability diagram of PRB flows in the Re-Ra plane, at $\operatorname{Pr}=0.7$ and for channels of large spanwise aspect ratios (for $B \geq 10$ ), is presented first in this paper (in Sec. II). This diagram is built from the theoretical and experimental literature results and also using the linear stability results of the present study. Indeed, in Sec. IV,

\footnotetext{
a) Author to whom correspondence should be addressed. Electronic mail: nicolas@univ-mlv.fr. Tel.: (33) 160957314 Fax: (33) 160957294.

b)E-mail: noussaibazoueidi@gmail.com.

c) E-mail: shihe.xin@insa-lyon.fr.
} 
Clever and Busse's time linear stability analysis ${ }^{10}$ of PRB longitudinal rolls between two infinite plates $(\mathrm{B} \rightarrow \infty)$ is extended to the case of air flows in confined channels for $\mathrm{B}=10$ and $70<\operatorname{Re}<$ 300. This analysis provides the critical Rayleigh number, $\mathrm{Ra} \approx *(\mathrm{Re})$, between the stable longitudinal rolls and their convective instability made of wavy rolls, as well as the critical streamwise wave number, $\mathrm{k}_{\mathrm{x}} *$, and critical frequency, $\mathrm{f}^{*}$.

The main objective of the paper, presented in Sec. V, is to characterize the nonlinear spatiotemporal behavior of the wavy instability of PRB flows, which is still very badly known, because it has been understood only recently that it is a convective instability of longitudinal rolls. ${ }^{8,9}$ As a consequence, wavy rolls can only be observed in an experimental channel in which longitudinal rolls are permanently excited, by mechanical or thermal devices for instance, and the typical features of the wavy rolls directly depend on the excitation type. In this paper, wavy convective instability is characterized using three-dimensional (3D) direct numerical simulations and random excitations at channel inlet. Prandtl number is fixed at $\operatorname{Pr}=0.7$ and channel spanwise aspect ratio at $\mathrm{B}=10$ in order to make comparisons with the experiments of Pabiou et al. ${ }^{9}$ The simulated ranges of Reynolds and Rayleigh numbers are $100 \leq \mathrm{Re} \leq 200$ and $4500 \leq \mathrm{Ra} \leq 15000$.

Since longitudinal rolls must be computed to study their destabilization towards wavy roll pattern, their nonlinear behavior is also analyzed for the same parameter ranges. This is interesting because longitudinal roll analyses in the literature are generally carried out for $\operatorname{Re}<100$ and $\mathrm{Ra}<10000$, i.e., for smaller $\mathrm{Re}$ and $\mathrm{Ra}$ ranges compared to the present ones. Furthermore, it is discovered that the usually used definitions to determine the growth lengths of longitudinal rolls are shorter than what should be called the appearance length of fully developed longitudinal rolls. A revised definition of the growth length is proposed in Sec. V C. We also explain the discrepancy, on wall averaged Nusselt number between the experimental and numerical results, observed at high Rayleigh number in fully developed "longitudinal roll" flows.

The determination of the most influencing perturbations on the downstream evolution of convected fields is a general problem as soon as convective instabilities are concerned. For instance, the influence of an external forcing coming from the channel inlet boundary condition, compared to that of an internal bulk thermal forcing, has been theoretically studied in Refs. 11 and 12. In the present paper, we only consider perturbations introduced at channel inlet because they are $a$ priori the most amplified in a channel of finite length. Thus, in a channel of fixed spanwise aspect ratio B and for a given fluid (Pr fixed), wavy roll characteristics should still depend on four parameters: $\mathrm{Ra}, \mathrm{Re}$, the forcing frequency, $\mathrm{f}_{\mathrm{exc}}$, and the forcing magnitude, $\mathrm{A}_{\mathrm{exc}}$. In order to reduce parameter number, instead of using a harmonic excitation like in Ref. 9, a random excitation (an uncorrelated white noise) is imposed at channel inlet. This excitation type has the advantage to only depend on one parameter, its magnitude $\mathrm{A}_{\mathrm{exc}}$, and to cover all the excitation frequencies. That allows detecting the modes that are naturally amplified by the flow and those that are damped. The linear and nonlinear characteristics of wavy rolls will be compared first between themselves and then to the experimental results of Ref. 9 and numerical and theoretical studies ${ }^{6,13,14}$ of the literature.

The outline of the paper is the following. A bibliographical review on the full stability diagram of $\mathrm{PRB}$ flows at $\mathrm{Pr}=0.7,0 \leq \mathrm{Re} \leq 300$, and $0 \leq \mathrm{Ra} \leq 20000$, in large spanwise aspect ratio channels (for $\mathrm{B} \geq 10$ ), is presented in Sec. II. The mathematical model for the nonlinear numerical analysis of PRB flows, including geometry, equations, and boundary conditions, is given in Sec. III. The results of the time linear stability analysis of longitudinal rolls vis-à-vis wavy rolls at $\operatorname{Pr}=0.71$ and B $=10$ are analyzed in Sec. IV. Section V concerns nonlinear numerical simulations of longitudinal and wavy rolls: numerical methods used and their validations are presented in Sec. V A; numerical simulations performed (flow and excitation parameters investigated) and simulation methodology are described in Sec. V B; longitudinal rolls are analyzed in Sec. V C; wavy rolls in Sec. V D (influence of excitation amplitude), and Sec. V E (influence of Re and $\mathrm{Ra}($ or $\varepsilon)$ ). A possible application of wavy roll flows to make more uniform films and coatings in rectangular CVD reactors is discussed in Sec. VI. Conclusions and perspectives are given in Sec. VII. 


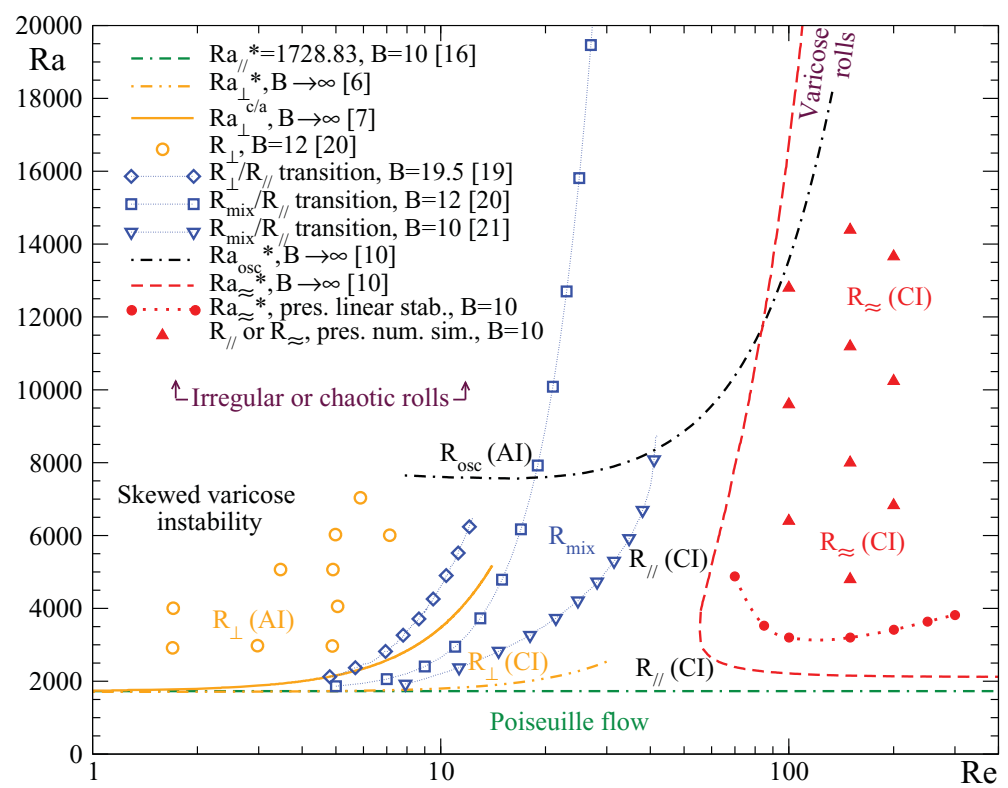

FIG. 1. Stability diagram of the thermoconvective patterns of $\mathrm{PRB}$ flows at $\mathrm{Pr}=0.7$ and $\mathrm{B} \geq 10$, built from the experimental, ${ }^{19-21}$ numerical, ${ }^{26}$ and linear stability, ${ }^{6,7,10,16}$ results and the present linear stability and numerical results. Bold lines are for theoretical results, open symbols for experimental results, and solid symbols for the present results. The critical Rayleigh numbers $\mathrm{Ra}^{*}{ }^{*}$ and $\mathrm{Ra}$ ? ${ }^{\mathrm{c} / \mathrm{a}}$ indicate a time linear instability threshold and a convective/absolute instability threshold, respectively, towards the instability described by the subscript symbol "?". $\mathrm{R}_{\perp}=$ transverse rolls; $\mathrm{R}_{/ /}=$longitudinal rolls; $\mathrm{R}_{\mathrm{mix}}=$ mixed transverse and longitudinal rolls; $\mathrm{R} \approx=$ wavy rolls; $\mathrm{R}_{\mathrm{osc}}=$ oscillating rolls; $\mathrm{CI}=$ convective instability; $\mathrm{AI}=$ absolute instability.

\section{BIBLIOGRAPHICAL REVIEW ON THE STABILITY DIAGRAM OF AIR PRB FLOWS IN LARGE ASPECT RATIO CHANNELS}

The stability diagram in the (Re, Ra) plane of PRB flows at $\operatorname{Pr}=0.7$ and $\mathrm{B} \geq 10$ or $\mathrm{B} \rightarrow \infty$ is presented in Fig. 1. In this figure and for all the literature results presented in this paper, the Reynolds number is based on the channel height $\mathrm{H}$ and the averaged velocity of Poiseuille flow and the Rayleigh number is based on $\mathrm{H}$ and the temperature difference between the channel horizontal walls. We focus on flows at $\operatorname{Pr}=0.7$ and large $\mathrm{B}$ values because most theoretical results are obtained for $\mathrm{B} \rightarrow \infty$ and because the available experiments ${ }^{9}$ for comparison are carried out with air and $\mathrm{B}=10$. Furthermore, the critical thresholds between two flow patterns are very sensitive to $\mathrm{B}$ values when $\mathrm{B}$ is small (for about $\mathrm{B}<8$ ), while the $\mathrm{B}$ influence becomes negligible when $\mathrm{B}$ is large (see Ref. 15 for the longitudinal roll flows). The stability diagram of Fig. 1 and the main References 5-9 that identified the convective or absolute nature of the primary and secondary instabilities are progressively commented on below.

Whatever Pr, a basic Poiseuille flow with a linear temperature profile is observed for $\mathrm{Ra} \leq 1708$ when $\mathrm{B} \rightarrow \infty$ and for $\mathrm{Ra} \leq 1728.83$ when $\mathrm{B}=10 .{ }^{16}$ For slightly higher Rayleigh numbers, the primary instabilities develop: transverse rolls are observed when $\mathrm{Re}$ is small and $\mathrm{B}$ is finite, and longitudinal rolls appear when Re is higher. ${ }^{17}$ Sometimes mixed rolls, superposition of transverse and longitudinal rolls, are present at intermediate Re values (see Fig. 1 and discussion below). It is well known that the time linear instability threshold, $\mathrm{Ra}_{\perp} *(\mathrm{Re})$, between basic Poiseuille flow and transverse rolls is an increasing function of Re (see the double dotted dashed orange line on Fig. 1) and corresponds to a convective instability. ${ }^{5,6,17,18}$ In practical terms, transverse rolls cannot appear just above this threshold, except if the basic Poiseuille flow is submitted to a permanent mechanical or thermal excitation. Without external excitations transverse rolls can appear only above the convective/absolute instability threshold, $\mathrm{Ra}_{\perp}{ }^{\mathrm{c} / \mathrm{a}}$, between the convectively and absolutely unstable Poiseuille flow (see the continuous orange line on Fig. 1). This critical threshold was 
first determined by Müller et al. ${ }^{5,6}$ using both a 1D Ginzburg-Landau model and 2D numerical simulations. By studying the long time behavior of the Green function, Carrière and Monkewitz ${ }^{7}$ confirmed that a transition from a convective to an absolute transverse instability occurs. They computed the curve $\mathrm{Ra}_{\perp}{ }^{\mathrm{c} / \mathrm{a}}$ for $\mathrm{B} \rightarrow \infty$. As shown in Fig. 1, this theoretical critical curve (in orange) is in good agreement with three experimental curves (in blue with open symbols) depicting the transition between the transverse and longitudinal rolls for $\mathrm{B}=19.5$ (Ref. 19) and between the mixed and longitudinal rolls for $\mathrm{B}=10$ and $12 .{ }^{20,21}$ These experimental curves also confirm that the larger B is, the smaller must be Re, to observe transverse or mixed rolls. ${ }^{17}$ In other words, the less there is spanwise confinement, the larger the Reynolds number range in which longitudinal rolls are observed is. At the limit, when $\mathrm{B} \rightarrow \infty$, Carrière and Monkewitz ${ }^{7}$ show that the longitudinal rolls are always the most amplified mode and result from a convective instability of the basic Poiseuille flow.

When B is enough small, a zone with transverse and longitudinal mixed rolls is observed in experiments ${ }^{20,21}$ between the zones of fully developed transverse and longitudinal rolls (see the blue dotted lines with open squares and triangles in Fig. 1). However, these mixed rolls would not be fully developed patterns of PRB flows when B is large. Indeed, in Ref. 20, they are only observed near the entrance of a channel which is too short to observe fully developed rolls downstream; the latter should probably be longitudinal rolls. On the other hand, in the case of a narrow square channel (B $=1$ ), Kato and Fujimura ${ }^{22}$ show by a time linear stability study of longitudinal rolls at $\mathrm{Pr}=0.71$ that mixed rolls are a secondary instability of longitudinal rolls.

Clever and Busse ${ }^{10}$ have shown through a time linear stability analysis that wavy rolls are a secondary instability of longitudinal rolls and are observed for $\mathrm{Ra}$ above and on the right of the dashed red critical curve, $\mathrm{Ra} \approx *$, in Fig. 1 (i.e., for about $\operatorname{Ra}>2000$ and $\operatorname{Re}>60 \sim 100$ at $\operatorname{Pr}=0.7$ and $\mathrm{B} \rightarrow \infty)$. However, before the studies by Pabiou et al., ${ }^{8,9}$ the wavy rolls had never been observed experimentally or numerically. An old experiment by $\mathrm{Avsec}^{23}$ is sometimes cited for the observation of wavy rolls. However, since flow parameters are not given in Ref. 23, it is impossible to confirm if the observed wavy patterns are wavy rolls. Furthermore, the photographs presented in Ref. 23 rather seem to suggest oscillating and varicose rolls (see below) which would be more logical since, as already mentioned, wavy rolls are a convective instability of the longitudinal rolls ${ }^{8,9}$ and can only appear if longitudinal rolls are permanently excited. This is the reason why a thin oscillating rod, generating harmonic mechanical excitations of controlled amplitude and frequency, had to be placed at channel inlet to trigger and to maintain the wavy rolls in the experiments of Refs. 8 and 9.

In a few experimental work about PRB flows in air or nitrogen, ${ }^{21,23,24}$ at low Reynolds number $(\mathrm{Re}<\mathrm{O}(30))$ and high Rayleigh number $\left(\mathrm{Ra}>8000\right.$ or $\left.\mathrm{Ra} \sim \mathrm{O}\left(10^{4}\right)\right)$, the spontaneous appearance of "oscillating," "snaking," or "unsteady irregular" rolls is briefly described. These rolls correspond most probably to the skewed varicose or oscillating rolls of small streamwise wavelength $\lambda_{x}$ (equal to 2-2.5 times the channel height) described at $\operatorname{Re} \leq 70$ in the linear stability study by Clever and Busse ${ }^{10,25}$ (see the dotted dashed black line of Fig. 1). The oscillating traveling rolls are an instability already present in Rayleigh-Bénard configuration (at $\operatorname{Re}=0$ ). However, in the case of the PRB configuration at $\operatorname{Pr}=0.7$, their phase velocity is negative for $\mathrm{Re} \leq 20$ (they travel in the direction opposite to the mean velocity) and positive for $\operatorname{Re}>20$. The pattern considered in the present study corresponds to the "wavy" rolls of long streamwise wavelength (of the order of 4-10 times the channel height) observed at high Reynolds number (for $\operatorname{Re} \geq 60-70$ in Ref. 10).

Figure 1 shows varicose rolls for $\mathrm{Re} \approx 100$ and $\mathrm{Ra} \sim 2 \times 10^{4}$. They are observed in 3D nonlinear numerical simulations for $\mathrm{B}=10$ and $\mathrm{B} \rightarrow \infty$, at $\operatorname{Pr}=0.7$ in Ref. 26. These rolls have small wavelengths as the oscillating rolls have but, unlike them, they oscillate with antiphase instead of oscillating in phase. Varicose rolls in air flows have also been observed experimentally in Refs. 23 and 27, numerically in Ref. 28, and by linear stability analysis in Ref. 22. However, in Refs. 22, 27, and 28, this pattern is observed for small spanwise aspect ratios and small Reynolds numbers: for B $=1, \operatorname{Re}<25$, and $\mathrm{Ra}>20000$ in Ref. 22, in which the varicose rolls are denoted by anti-symmetric instability, and for $2 \leq \mathrm{B}<6$, Re $<10-20$, and $5000<\mathrm{Ra}<20000$ in Refs. 27 and 28. But varicose rolls are no longer observed when $\mathrm{B} \geq 8$ in Refs. 27 and 28. In Ref. 26, for B $\geq 10$, irregular or chaotic patterns are observed numerically at small Reynolds number $(\operatorname{Re} \leq 70)$ and high Rayleigh number $\left(\mathrm{Ra}>10^{4}\right)$ (in the zone covered by the legend in Fig. 1). In this zone, PRB flows are very 


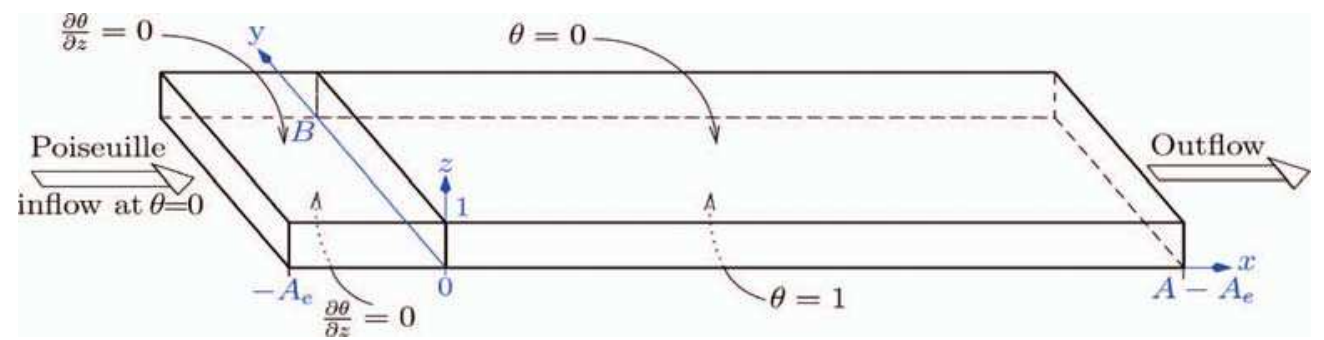

FIG. 2. Dimensionless geometry and thermal boundary conditions. The vertical lateral walls at $\mathrm{y}=0$ and $\mathrm{B}$ are adiabatic all along the channel.

unstable and no clear pattern is observed because there is a competition between the parameters Ra, $\mathrm{Re}$, and $\mathrm{B}$ to organize the flow structure.

Globally, it can be noted that the stability diagram of Fig. 1 at $\mathrm{B} \geq 10$ is qualitatively similar to the stability diagram built through a linear stability analysis by Kato and Fujimura ${ }^{22}$ for $\mathrm{B}=1$ and $\operatorname{Pr}=0.71$. The main differences appear in the increase of the transition thresholds towards higher Rayleigh numbers in Ref. 22 due to the stabilizing effect of the small spanwise aspect ratio used. Both the primary transition between the basic Poiseuille flow and the transverse, longitudinal and mixed rolls and the secondary transition towards the oscillating, wavy, or varicose rolls are affected by this increase.

\section{PROBLEM DESCRIPTION AND MATHEMATICAL MODEL}

The computational domain considered to simulate PRB flows is shown in Fig. 2. It is a horizontal rectangular channel of height $\mathrm{H}$, width $\mathrm{W}$, and length $\mathrm{L}$, heated from below. A fully developed Poiseuille flow enters into the channel at cold temperature $T_{c}$, with an average velocity $U_{\text {mean }}$. After an adiabatic entrance zone of length $\mathrm{L}_{e}$, the top wall is maintained at $\mathrm{T}_{\mathrm{c}}$ and the bottom wall is heated at a higher temperature $T_{h}$. The vertical lateral walls are adiabatic all along the channel. The origin of the reference frame being placed at the beginning of the heated plate, the computational domain is defined by $(\mathrm{x}, \mathrm{y}, \mathrm{z}) \in\left[-\mathrm{A}_{\mathrm{e}}, \mathrm{A}-\mathrm{A}_{\mathrm{e}}\right] \times[0, \mathrm{~B}] \times[0,1]$ in dimensionless Cartesian coordinates, where $A=L / H$ and $B=W / H$ are the streamwise and spanwise aspect ratios and $A_{e}=L_{e} / H$ is the streamwise entrance aspect ratio.

Lengths, velocities, pressure, and time are made dimensionless using $\mathrm{H}, \mathrm{U}_{\text {mean }}, \rho \mathrm{U}_{\text {mean }}{ }^{2}$, and $\mathrm{H} / \mathrm{U}_{\text {mean }}$, respectively, as reference quantities. Furthermore, $\theta=\left(\mathrm{T}-\mathrm{T}_{\mathrm{c}}\right) /\left(\mathrm{T}_{\mathrm{h}}-\mathrm{T}_{\mathrm{c}}\right)$ is the reduced temperature. Note that the ratio $\mathrm{U}_{\text {meam }} / \mathrm{U}_{\max }$ of the average and maximum Poiseuille velocities in a channel of $\mathrm{B}=10$ is equal to $0.936975 .{ }^{17}$ In the present study, we consider PRB flows of incompressible Newtonian pure fluids, governed by the 3D Navier-Stokes equations under the Boussinesq approximation. Thus the dimensionless equations for continuity, momentum, and energy write as follows:

$$
\begin{aligned}
& \nabla \cdot \overrightarrow{\mathrm{v}}=0, \\
& \frac{\partial \overrightarrow{\mathrm{v}}}{\partial \mathrm{t}}+(\overrightarrow{\mathrm{v}} \cdot \nabla) \overrightarrow{\mathrm{v}}=-\nabla \mathrm{p}+\frac{1}{\operatorname{Re}} \nabla^{2} \overrightarrow{\mathrm{v}}+\frac{\operatorname{Ra}}{\operatorname{Re}^{2} \operatorname{Pr}} \theta \overrightarrow{\mathrm{k}}, \\
& \frac{\partial \theta}{\partial \mathrm{t}}+\overrightarrow{\mathrm{v}} \cdot \nabla \theta=\frac{1}{\operatorname{Re} \operatorname{Pr}} \nabla^{2} \theta,
\end{aligned}
$$

where $\overrightarrow{\mathrm{v}}=(\mathrm{u}, \mathrm{v}, \mathrm{w})$ is the dimensionless velocity vector, $\overrightarrow{\mathrm{k}}$ is the upward unit vector, and $\mathrm{p}$ is the deviation of the mixture pressure from the hydrostatic pressure. Ra $=\mathrm{g} \beta\left(\mathrm{T}_{\mathrm{h}}-\mathrm{T}_{\mathrm{c}}\right) \mathrm{H}^{3} /(v \alpha)$, $\operatorname{Re}=\mathrm{U}_{\text {mean }} \mathrm{H} / \nu$, and $\operatorname{Pr}=\nu / \alpha$, where $\mathrm{g}, \beta, \nu$, and $\alpha$ are the gravity acceleration, the thermal expansion coefficient, the kinematic viscosity, and the thermal diffusivity, respectively.

The boundary conditions are

$$
\text { at } \mathrm{x}=-\mathrm{A}_{\mathrm{e}}, \mathrm{u}=\mathrm{u}_{\text {Pois }}(\mathrm{y}, \mathrm{z}), \mathrm{v}=\mathrm{w}=0 \text {, or } \mathrm{v}=\mathrm{w}=\text { white noise (see Sec. V B and } \theta=0 \text {, }
$$




$$
\begin{aligned}
& \text { at } \mathrm{y}=0 \text { and } \mathrm{B}, \overrightarrow{\mathrm{v}}=\overrightarrow{0} \text { and } \partial \theta / \partial \mathrm{y}=0, \\
& \text { at } \mathrm{z}=0 \text { and } 1 \text {, for } \mathrm{x} \in\left[-\mathrm{A}_{\mathrm{e}}, 0\right], \overrightarrow{\mathrm{v}}=\overrightarrow{0} \text { and } \partial \theta / \partial \mathrm{z}=0 \text {, } \\
& \text { at } \mathrm{z}=1 \text {, for } \mathrm{x} \in\left[0, \mathrm{~A}-\mathrm{A}_{\mathrm{e}}\right], \overrightarrow{\mathrm{v}}=\overrightarrow{0} \text { and } \theta=0, \\
& \text { at } \mathrm{z}=0 \text {, for } \mathrm{x} \in\left[0, \mathrm{~A}-\mathrm{A}_{\mathrm{e}}\right], \overrightarrow{\mathrm{v}}=\overrightarrow{0} \text { and } \theta=0, \\
& \text { at } \mathrm{x}=\mathrm{A}-\mathrm{A}_{\mathrm{e}}, \partial \mathrm{f} / \partial \mathrm{t}+\partial \mathrm{f} / \partial \mathrm{x}=0 \text { for } \mathrm{f}=\mathrm{u}, \mathrm{v}, \mathrm{w} \text {, and } \theta \text {. }
\end{aligned}
$$

In Eq. (4), at the inlet, $\mathrm{u}_{\mathrm{Pois}}(\mathrm{y}, \mathrm{z})$ is an approximation of the Poiseuille profile in a rectangular channel computed from a truncated analytical series as explained in Ref. 29. In Eq. (9), at the outlet, the Orlanski-type boundary conditions are used. The conditions (4) and (9) at the two limits in $x$ direction and the adiabatic entrance length (6) are only used in the nonlinear simulations to study the space and time development of the mixed convection rolls. In the time linear stability analysis, a computational domain entirely heated from below and cooled from above and periodic boundary conditions in the streamwise direction are used (see Ref. 16 for the mathematical model in this case).

To analyze heat transfer associated with the mixed convection, local Nusselt numbers $\mathrm{Nu}(\mathrm{x} ; \mathrm{y}$; $\mathrm{z}=0$ or 1 ) are computed on the bottom and top plates as

$$
\mathrm{Nu}(\mathrm{x} ; \mathrm{y} ; \mathrm{z}=0,1)=\left.\frac{\mathrm{H}}{\left(\mathrm{T}_{\mathrm{h}}-\mathrm{T}_{\mathrm{c}}\right)} \frac{\partial \mathrm{T}}{\partial \mathrm{Z}}\right|_{\mathrm{Z}=0, \mathrm{H}}=\left.\frac{\partial \theta}{\partial \mathrm{z}}\right|_{z=0,1} .
$$

The spanwise averaged Nusselt number $\overline{\mathrm{Nu}}(\mathrm{x} ; \mathrm{z}=0$ or 1$)$ and the averaged Nusselt number in the fully developed region, $\overline{\mathrm{Nu}}_{\mathrm{fd}}(\mathrm{z}=0,1)$, are also used. They are defined as

$$
\begin{aligned}
& \overline{\mathrm{Nu}}(\mathrm{x} ; \mathrm{z}=0,1)=\frac{1}{\mathrm{~B}} \int_{\mathrm{y}=0}^{\mathrm{B}} \mathrm{Nu}(\mathrm{x} ; \mathrm{y} ; \mathrm{z}=0,1) \mathrm{dy}, \\
& \overline{\mathrm{Nu}}_{\mathrm{fd}}(\mathrm{z}=0,1)=\frac{1}{\mathrm{~A}-\mathrm{A}_{\mathrm{e}}-\mathrm{L}_{\mathrm{e}}^{+}} \int_{\mathrm{x}=\mathrm{L}_{\mathrm{e}}^{+}}^{\mathrm{x}=\mathrm{A}-\mathrm{A}_{\mathrm{e}}} \overline{\mathrm{Nu}}(\mathrm{x} ; \mathrm{z}=0,1) \mathrm{dx},
\end{aligned}
$$

where $\mathrm{L}_{\mathrm{e}}{ }^{+}$is a dimensionless length larger than the growth length of the mixed convection rolls (longitudinal or wavy) that will be defined in Secs. V C and V D. In the case of unsteady wavy roll flows, Nusselt numbers (11) and (12) are in addition averaged in time over the whole third step of the simulations (see Sec. V B) during which the wavy roll flows are fully established.

\section{LINEAR STABILITY ANALYSIS OF THE LONGITUDINAL ROLLS VIS-À-VIS THE WAVY ROLLS}

The methodology used to carry out linear stability of longitudinal rolls in confined PRB flows is based on steady-state solving to compute base solutions, Arnoldi's method to search the eigenvalues, continuation methods to precisely determine the critical points and time-stepping methods to determine nonlinear behavior and bifurcation nature. All these methods have been detailed in Ref. 16. In Ref. 16, time linear stability of longitudinal rolls submitted to three-dimensional perturbations in a channel of finite spanwise extension was studied for a unique PRB flow at $\operatorname{Re}=200, \mathrm{~B}=10$, and $\operatorname{Pr}=0.71$. Three stable solution branches with 9 , 10, or 11 longitudinal rolls were discovered, all of them being unstable with respect to the wavy instabilities. Nonlinear simulations have also shown that the corresponding Hopf bifurcations are supercritical and result in 9,10 , or 11 wavy rolls, respectively.

However, this result is biased because space development of the rolls is not taken into account by the time linear analysis. When it is considered, in experiments or in numerical simulations, it 
TABLE I. Dimensionless parameters and wavy roll critical characteristics at linear threshold for $\mathrm{B}=10$ and $\mathrm{Pr}=0.71$.

\begin{tabular}{lcccc}
\hline \hline $\operatorname{Re}$ & $\mathrm{Ra} \approx^{*} \pm 0.01$ & $\mathrm{k}_{\mathrm{x}}^{*} \pm 0.0001$ & $\mathrm{f}^{*} \pm 0.00002$ & $\mathrm{c}^{*}=2 \pi \mathrm{f}^{*} / \mathrm{k}_{\mathrm{x}}^{*} \pm 0.0003$ \\
\hline 70 & 4882.23 & 0.3864 & 0.69176 & 1.1248 \\
85 & 3522.09 & 0.7648 & 0.13632 & 1.1199 \\
100 & 3199.87 & 0.8385 & 0.14922 & 1.1182 \\
150 & 3198.90 & 0.8268 & 0.14507 & 1.1024 \\
200 & 3414.62 & 0.8174 & 0.14105 & 1.0843 \\
250 & 3635.99 & 0.8224 & 0.14004 & 1.0699 \\
300 & 3819.46 & 0.8279 & 0.13979 & 1.0609 \\
\hline \hline
\end{tabular}

is well known ${ }^{1}$ that only an even number of rolls can develop in the channel. This was justified in Ref. 30 and has recently been studied by Mergui et al. ${ }^{15}$ who have shown experimentally and numerically that only ten longitudinal rolls can develop in air when $\mathrm{B}=10$ and the fluid is cold at channel entrance. As a consequence, only the solution branch with ten longitudinal or wavy rolls is considered in the present study.

To be able to draw the neutral curve $\mathrm{Ra} \approx *(\mathrm{Re})$ between the longitudinal and wavy rolls for a wide range of $\mathrm{Re}$, the same linear stability analysis as in Ref. 16 has been repeated for $\operatorname{Re}=70,85,100,150,250$, and 300. The critical values of $\mathrm{Ra} \approx *$ and of the dimensionless streamwise wave numbers, $\mathrm{k}_{\mathrm{x}}{ }^{*}$, frequencies, $\mathrm{f}^{*}$, and phase velocities, $\mathrm{c}^{*}$, of the wavy rolls at the linear critical threshold are given in Table I. The critical curve $\mathrm{Ra} \approx *(\mathrm{Re})$ is also drawn with a red dotted line in Fig. 1. Its minimum value (obtained using a cubic spline interpolation between the points of Table I) is $\mathrm{Ra}_{\approx}^{*} \approx 3130$ at $\mathrm{Re} \approx 120$ for $\mathrm{B}=10$, whereas $\mathrm{Ra}^{*} *=2179$ at $\mathrm{Re}=120$ for $\mathrm{B} \rightarrow \infty$ [10]. At $\mathrm{Re}=300, \mathrm{Ra} \approx^{*}=3819.5$ for $\mathrm{B}=10$, whereas $\mathrm{Ra} \approx^{*}=2127$ for $\mathrm{B} \rightarrow \infty$. The lateral confinement of the channel has, therefore, an important influence on the critical threshold, even at a quite large aspect ratio $\mathrm{B}=10$. More important is the fact that the critical wave number $\mathrm{k}_{\mathrm{x}}{ }^{*}$ vanishes when $\mathrm{B} \rightarrow \infty[10]$, whereas $\mathrm{k}_{\mathrm{x}} *$ has always finite values when $\mathrm{B}=10$. At $\mathrm{B}=10, \mathrm{k}_{\mathrm{x}}$, and $\mathrm{f}^{*}$ strongly increase with Re for small Re values. As far as the phase velocity is concerned, it remains nearly constant, equal to $\mathrm{c}^{*} \approx 1.1$ whatever $\mathrm{Re}$. This value is the same as the one measured experimentally in Ref. 9 for nonlinear cases (see Sec. V E).

\section{NONLINEAR NUMERICAL SIMULATIONS WITHOUT AND WITH AN INLET RANDOM EXCITATION}

\section{A. Numerical methods and validations}

The governing equations (1)-(3) with the boundary conditions (4)-(9) have been solved using a finite difference method optimized for vectorial computers. ${ }^{31}$ They are discretized in time and space by second-order schemes. Time discretization uses a second-order backward difference formula for the time derivative term, an explicit Adams-Bashforth scheme for the convective term and an implicit treatment of the diffusive term. Centered differences for the diffusive terms and a central scheme for the convective terms are applied on uniform, Cartesian and staggered grids. Typical dimensionless cell sizes are $\Delta \mathrm{x} \times \Delta \mathrm{y} \times \Delta \mathrm{z}=0.1 \times 0.055 \times 0.029$ and the node number is $\mathrm{N}_{\mathrm{x}} \times \mathrm{N}_{\mathrm{y}} \times \mathrm{N}_{\mathrm{z}}$ $=2001 \times 181 \times 35$ when the channel aspect ratios are $\mathrm{A}=200$ and $\mathrm{B}=10$. Typical dimensionless time step is $\Delta \mathrm{t}=0.01$.

Time integration and velocity-pressure coupling are solved by a projection method based on Goda's algorithm. The Helmholtz equations for the temperature field and the components of the predicted velocity field are solved using an incremental factorization method of ADI type which permits to keep a second-order time accuracy. The Poisson equation for the pressure increment is solved by partially diagonalizing the mono-dimensional Laplace operators in the transverse directions y and $\mathrm{z}$. The linear systems resulting from these two methods are all tridiagonal and are solved by TDMA algorithm. Since this solver is highly vectorizable, the code is very efficient on the NEC-SX8 vectorial supercomputer used: it runs at 12.5 Giga Flops on average, when the 
TABLE II. Parameters of the 13 PRB flow cases computed by 3D nonlinear numerical simulations in the present paper.

\begin{tabular}{|c|c|c|c|c|c|}
\hline Case \# & $\operatorname{Re}$ & $\mathrm{Ra}$ & $\varepsilon$ & $\mathrm{A}_{\mathrm{exc}}$ & $\mathrm{A}=\mathrm{L} / \mathrm{H}$ \\
\hline 1 & 100 & 6396 & 1 & 0.1 & 300 \\
\hline 2 & 100 & 9594 & 2 & 0.1 & 200 \\
\hline 3 & 100 & 12792 & 3 & 0.1 & 200 \\
\hline 4 & 150 & 4792 & 0.5 & 0.1 & 350 \\
\hline 5 & 150 & 7986 & 1.5 & 0.1 & 200 \\
\hline 6 & 150 & 11181 & 2.5 & 0.1 & 200 \\
\hline 7 & 150 & 14375 & 3.5 & 0.1 & 200 \\
\hline 8 & 200 & 6829 & 1 & 0.1 & 300 \\
\hline $9,10,11,12$ & 200 & 10244 & 2 & $0.02,0.1,0.5,2$ & 200 \\
\hline 13 & 200 & 13658 & 3 & 0.1 & 200 \\
\hline
\end{tabular}

crest power of this computer is 16 Giga Flops and the computational cost of the solution for one mesh point and one time step is equal to $10^{-7} \mathrm{~s}$. A detailed description of this code, its validations and its performances can be found in Ref. 31. Furthermore, the same code has also contributed to the computation of a benchmark solution of a PRB flow, in the case of a longitudinal roll flow configuration, in Refs. 29 and 32.

As studying spatiotemporal evolution of the wavy rolls requires both long channels and high space resolutions, several tests of the space and time discretizations have been carried out to determine the best compromise between solution accuracy and computational cost. The most restrictive constraints have appeared on the streamwise space step, $\Delta \mathrm{x}$, and time step, $\Delta \mathrm{t}$, necessary to catch the appropriate characteristics of the wavy rolls. Thus, for three flow configurations corresponding to the case numbers 3, 6, and 10 in Table II, we have compared the solutions obtained on three grids, with $\Delta \mathrm{x}=0.2,0.1$, and 0.05 , and for two time steps, $\Delta \mathrm{t}=0.02$ and 0.01 , with $\Delta \mathrm{y}$ fixed at $\Delta \mathrm{y}=0.05$ or 0.055 , and $\Delta \mathrm{z}$ fixed at $\Delta \mathrm{z}=0.025$ or 0.029 . The solution computed with the finest discretization $(\Delta \mathrm{x} \times \Delta \mathrm{y} \times \Delta \mathrm{z}=0.05 \times 0.055 \times 0.029$ and $\Delta \mathrm{t}=0.01)$ has been considered as reference solution. Then the relative errors between the solutions computed with the coarsest discretizations and the reference solution have been computed. The maximum relative errors among the three flow configurations cited above on the different wavy roll characteristics analyzed in this paper (defined below in Secs. V C and V D) are presented in Table III as a function of the different tested discretizations. Whatever the used discretization, the maximum relative errors are observed on the growth lengths of wavy rolls $\left(\mathrm{L}_{\mathrm{Vs} / 2}, \mathrm{~L}_{\mathrm{Vs}}\right)$, on the amplitude of their spanwise displacements $\left(\mathrm{D} \theta_{\max }, \mathrm{D} \theta_{\text {mean }}\right)$, and on the averaged power of the Fourier spectra of their spanwise velocity in the fully developed zone $\left(\mathrm{P}_{\mathrm{av}}\left(\mathrm{v}_{\mathrm{fd}}\right)\right)$. On the other hand, the errors are much smaller on the wavy roll fundamental frequency $\left(\mathrm{f}^{\circ}\right)$, wave number $\left(\mathrm{k}_{\mathrm{x}}{ }^{\circ}\right)$, phase velocity $\left(\mathrm{c}^{\circ}\right)$, and saturation spanwise velocity $\left(\mathrm{V}_{\mathrm{s}}\right)$. Considering the whole quantities, the maximum relative errors vary between $7 \%$ and $26 \%$ with the coarsest grid and time step $(\Delta \mathrm{x}=0.2, \Delta \mathrm{t}=0.02)$. They vary between $2 \%$ and $13 \%$ using a finer grid $(\Delta \mathrm{x}=0.1)$ and the same time step $(\Delta \mathrm{t}=0.02)$ and between $1 \%$ and $7 \%$ when $\Delta \mathrm{x}=0.1$ and $\Delta \mathrm{t}=0.01$. We therefore consider that the best compromise is obtained with the latter discretizations. All the results presented in this paper are thus obtained with $\Delta \mathrm{x} \times \Delta \mathrm{y} \times \Delta \mathrm{z}=0.1$ $\times 0.055 \times 0.029$ or $0.05 \times 0.055 \times 0.029$ and $\Delta t=0.01$. Note that other tests have also permitted

TABLE III. Maximum relative error (in percentage\%) on the different wavy roll characteristics between the solutions computed with the current $\Delta \mathrm{x}$ and $\Delta \mathrm{t}$ discretizations and the finest reference discretization defined by $\Delta \mathrm{x}=0.05$ and $\Delta \mathrm{t}=0.01$. For all the grids of this table, $\Delta \mathrm{y}=0.05$ or 0.055 and $\Delta \mathrm{z}=0.025$ or 0.029 .

\begin{tabular}{cccccccccccc}
\hline \hline$\Delta \mathrm{x}$ & $\Delta \mathrm{t}$ & $\mathrm{f}^{\circ}$ & $\mathrm{k}_{\mathrm{x}}{ }^{\circ}$ & $\mathrm{c}^{\circ}$ & $\mathrm{V}_{\mathrm{s}}$ & $\mathrm{LV}_{\mathrm{V} / 2}$ & $\mathrm{LVs}_{\mathrm{s}}$ & $\mathrm{D} \theta_{\max }$ & $\mathrm{D} \theta_{\text {mean }}$ & $\mathrm{P}_{\mathrm{av}}\left(\mathrm{v}_{\mathrm{fd}}\right)$ & $\overline{\mathrm{Nu}}_{\mathrm{fd}}$ \\
\hline 0.2 & 0.02 & 7 & 9 & 7 & 10 & 23 & 21 & 14 & 18 & 26 & $<2$ \\
0.1 & 0.02 & 6 & 6 & 2.1 & 3 & 11 & 12 & 7 & 13 & 6 & $<2$ \\
0.1 & 0.01 & 1.4 & 2.0 & 1.6 & 2.4 & 3.4 & $<1$ & 7 & 7 & 6 & $<2$ \\
\hline \hline
\end{tabular}


to check that the vertical space step $\Delta z=0.029$ is sufficiently small to compute the wall Nusselt numbers with $2 \%$ accuracy compared with much finer grids in $\mathrm{z}$ direction. ${ }^{29,32}$

\section{B. Nonlinear numerical simulations performed and simulation methodology}

Nonlinear simulations presented in this paper concern the space and time development of longitudinal and wavy roll flows at $\operatorname{Pr}=0.71$, in channels of aspect ratios $A=200-350, A_{e}=1$ and $\mathrm{B}=10$. They are performed for ten couples of Re-Ra (see Table II) that are represented by red filled triangles in Fig. 1. In Table II, $\varepsilon$ is the relative distance to the critical Rayleigh number, $\mathrm{Ra} \approx *(\mathrm{Re})$, listed in Table I: $\varepsilon=(\operatorname{Ra}-\mathrm{Ra} \approx *(\mathrm{Re})) / \mathrm{Ra} \approx *(\mathrm{Re})$. The ten couples of Re-Ra chosen form a Doehlert's design of experiment in the $(\operatorname{Re}, \varepsilon)$ plane: $:^{33}$ they are placed at the vertices and centers of two joined hexagons. This will allow us to build optimized interpolation surfaces in order to fit the results in the $(\operatorname{Re}, \varepsilon)$ plane (see Sec. V E).

Each nonlinear simulation consists of three steps. In the first one, without introducing any excitation in the channel, a fully developed longitudinal roll flow is simulated by using a cold Poiseuille flow as initial condition in the whole channel and imposing $\theta=1$ at $\mathrm{z}=0$ and $\mathrm{x} \in[0$, A- $A_{e}$ ] for $t>0$. Streamwise growth lengths and heat transfers associated with these longitudinal patterns are analyzed in next Subsection V C.

In the second step, a permanent random excitation is introduced on the transverse velocity components, $\mathrm{v}$ and $\mathrm{w}$, of the inlet Poiseuille profile at $\mathrm{x}=-\mathrm{A}_{\mathrm{e}}$, in order to develop the wavy rolls in longitudinal roll flows. The second step ends when fully developed wavy rolls are present in the whole channel. This is an intermittent flow phase which is not analyzed here. In the third step, random excitation is maintained at the channel inlet and a fully developed wavy roll flow keeps being observed in the channel. The data of the third step, in particular the time signals recorded to perform Fourier analyses, are analyzed in Secs. V D and V E.

The random inlet excitation, imposed independently on $\mathrm{v}$ and $\mathrm{w}$ at each time step, is an uncorrelated white noise of maximum amplitude $\mathrm{A}_{\mathrm{exc}}\left(\mathrm{A}_{\mathrm{exc}}\right.$ is made dimensionless by the reference velocity $\mathrm{U}_{\text {mean }}$ ). This time noise is uniform at all points of the entrance plane: it simulates a grid that randomly moves in the entrance plane at each time step, generating a uniform transverse velocity vector added to the axial Poiseuille flow. The excitation magnitude influence is analyzed in Sec. V D for $A_{\text {exc }}=0.02,0.1,0.5$, and 2 at $(R e, R a)=(200,10244)$ (cases 9-12 of Table II).

To characterize the fully developed wavy roll flows that develop from the inlet random excitation, the spanwise velocity component, $\mathrm{v}$, has been recorded at each time step, during 20 000-25 000 iterations, at all computing points of the channel axis (2000 points at $(y, z)=(B / 2,0.5)$ for $A=200$ ). These time signals are analyzed through Fourier transforms to determine the spatial evolution of Fourier spectra in the wavy roll flows. Since $\Delta t=0.01$ and the dimensionless recording duration, $\mathrm{t}_{\max }$, varies between 200 and 250 , the highest frequency, $\mathrm{f}_{\max }$, and the frequency step, $\Delta \mathrm{f}$, of Fourier spectra are: $\mathrm{f}_{\max }=1 /(2 \Delta \mathrm{t})=50$ and $\Delta \mathrm{f}=1 / \mathrm{t}_{\max }=4 \times 10^{-3}-5 \times 10^{-3}$. As will be seen below, the range of the amplified frequencies in the Fourier spectra varies between 0.15 and 0.25 (the corresponding period varies between 4 and 6.67). Therefore, the recorded signals comprise 40-50 time periods on average and, with $\Delta \mathrm{t}$ used, one amplified period contains at minimum 333 time steps: we have checked that this is enough to provide a Fourier analysis independent of $\Delta t$ and $\mathrm{t}_{\max }$.

\section{Analysis of the longitudinal roll pattern}

Longitudinal roll flows are the most studied pattern of PRB flows (see Refs. 1, 10, 15, 16, 27, $29,30,34$, and 35 among others) because they are the most common one. Indeed, since the wavy rolls are a convective instability of the longitudinal rolls, the longitudinal rolls are the stable pattern of the non-excited PRB flows for the zones denoted by both " $\mathrm{R}_{/ /}(\mathrm{CI})$ " and "R $\approx(\mathrm{CI})$ " in Fig. 1. That is to say, without flow excitation, the longitudinal rolls are the stable pattern of PRB flows at $\operatorname{Pr}=0.7$ and $\mathrm{B} \geq 10$ approximately for $1730<\mathrm{Ra}<8000$ at $\mathrm{Re}=20$, for $1730<\mathrm{Ra}<13000$ at $\operatorname{Re}=100$, and for $1730<\operatorname{Ra}<20000$ or more when $\operatorname{Re}>100$. 


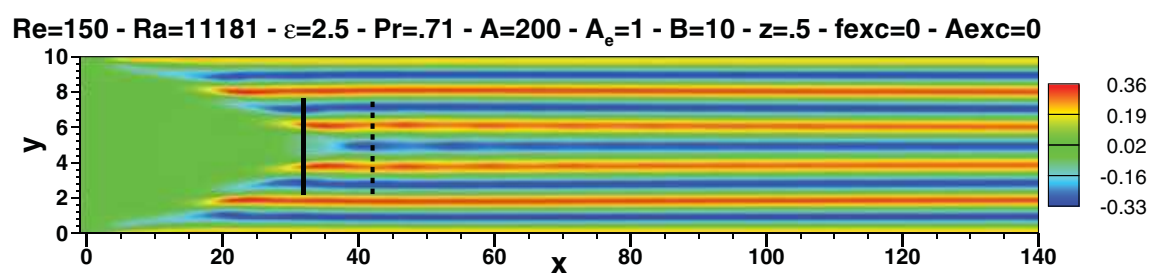

FIG. 3. Vertical velocity component in the horizontal mid-plane of the channel $(z=0.5)$ for a longitudinal roll flow whose parameters are given above the figure. Red and blue lines indicate positive and negative w values, respectively. For $\mathrm{x}>42$, ten fully developed longitudinal rolls appear since there is one roll between two successive red and blue lines. Streamwise growth lengths of the rolls $\mathrm{L}_{\mathrm{R} / /}\left[95 \% \overline{\mathrm{Nu}}_{\mathrm{fd}}(\mathrm{z}=0)\right]=31.3$ and $\mathrm{L}_{\mathrm{R} / /}\left[\mathrm{Nu}_{\max }(\mathrm{y}=5 ; \mathrm{z}=0)\right]=41.9$ are indicated by the continuous and dashed lines, respectively.

In the present subsection, the influences of Re and $\mathrm{Ra}$ on the streamwise growth length of the longitudinal rolls, $\mathrm{L}_{\mathrm{R} / /}$, made dimensionless by $\mathrm{H}$, and on the averaged wall Nusselt numbers, $\overline{\mathrm{Nu}}(\mathrm{x})$ and $\overline{\mathrm{Nu}}_{\mathrm{fd}}$ (see Eqs. (11) and (12)), are analyzed. The present numerical results obtained at $\mathrm{B}=10, \mathrm{Pr}$ $=0.7,100 \leq \mathrm{Re} \leq 200$, and $4500 \leq \mathrm{Ra} \leq 15000$ are compared with the literature results ${ }^{21,24,34,35}$ also obtained at $\mathrm{B} \approx 10$ and $\operatorname{Pr} \approx 0.7$ but for smaller $\operatorname{Re}$ and $\operatorname{Ra}: \operatorname{Re}<120$ and $\operatorname{Ra}<10000$. The aim is to both validate our numerical simulations and extend the correlations $L_{R / /}=f(R e, R a)$ and $\overline{\mathrm{Nu}}=\mathrm{f}(\mathrm{Ra})$ of the literature to wider parameter ranges.

The 2D field of the vertical velocity component, w, on the horizontal plane at the channel midheight and a three-dimensional picture of the streamlines and thermal field are presented in Figs. 3 and 4 for the steady longitudinal roll flow at $\mathrm{Re}=150$ and $\mathrm{Ra}=11181$. Near the channel entrance, for $\mathrm{x}<40$, a triangular forced convection zone in which flow remains parallel to the horizontal walls $(\mathrm{w}=0)$ appears. Convectively unstable longitudinal rolls are triggered near the vertical walls, just

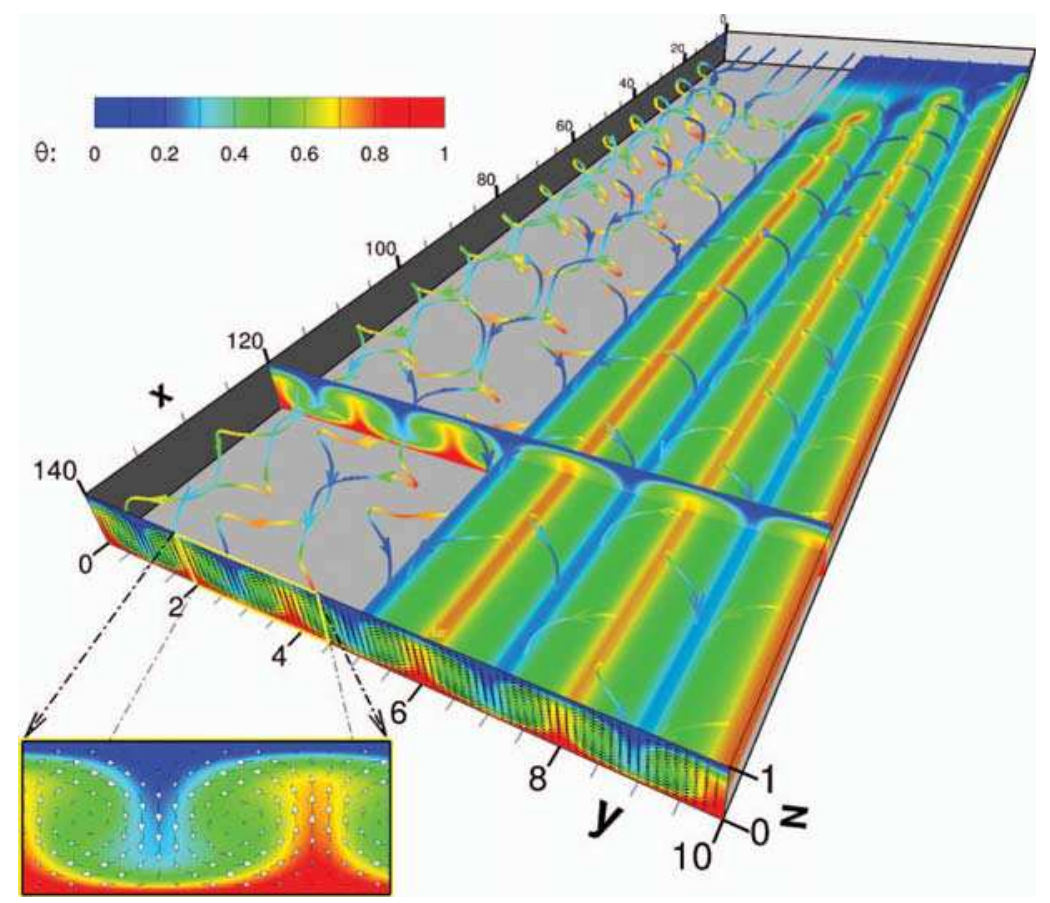

FIG. 4. 3D picture of the longitudinal roll flow of Fig. 3. The $2 \mathrm{D}$ temperature field, $\theta$, is drawn in the half-plane at $\mathrm{z}=0.5$ and in the planes at $\mathrm{x}=120$ and 140 (red is hot air and blue is cold). 2D velocity vectors are drawn and superimposed to the temperature field at $\mathrm{x}=140$ (a zoom in is shown in the inset). Ten streamlines colored by temperature field are also shown from inlet. 
downstream the entrance, due to a thermal instability in the boundary layers. Indeed, since the inlet temperature is cold, in the zone located just downstream and just above the beginning of the heated plate, the fluid particles inside the velocity boundary layers of the vertical walls are slower and hotter than the faster particles located outside this same boundary layer. As a consequence, it appears a destabilizing spanwise thermal gradient that generates an ascending longitudinal roll along the two vertical walls at entrance (read Ref. 15 for more details). Further downstream, the longitudinal rolls propagate from the vertical walls towards the channel core, as a gear (adjacent rolls counter-rotate), forming this characteristic triangular zone near the entrance.

It is well known that the length, $\mathrm{L}_{\mathrm{R} / /}$, necessary to get fully established longitudinal rolls increases when Re and $B$ increase or Ra decreases. However, the definition of $L_{R / /}$ varies a lot according to the authors. In their laser Doppler velocimetry (LDV) experiments in nitrogen, Chiu and Rosenberger ${ }^{21}$ define $L_{R / /}$ as the distance from the entrance to a point where the modulation amplitude of the spanwise profile of the streamwise velocity component, $\mathrm{u}$, at $\mathrm{z}=0.5$ reaches $95 \%$ of the modulation amplitude of the same profile in the fully developed region. The correlation of $\mathrm{L}_{\mathrm{R} / /}$ established in Ref. 21 is valid for $\mathrm{B}=9.6, \operatorname{Pr} \approx 0.7,15 \leq \mathrm{Re} \leq 120$, and $2470<\mathrm{Ra} \leq 8300$. It writes

$$
\mathrm{L}_{\mathrm{R} / /}=0.68[(\mathrm{Ra}-1708) / 1708]^{-0.69} \mathrm{Re}^{0.96} .
$$

Narusawa ${ }^{34}$ numerically reproduces the experiments. ${ }^{21}$ By keeping the same definition of $L_{R / /}$, he gets a slightly different correlation for the same parameter range

$$
\mathrm{L}_{\mathrm{R} / /}=0.6137[(\mathrm{Ra}-1708) / 1708]^{-0.69} \mathrm{Re} .
$$

Pabiou $^{36}$ and Pabiou et al. ${ }^{9}$ also perform visualization experiments of PRB air flows seeded with oil particles in a channel of $\mathrm{B}=10$. They determine $\mathrm{L}_{\mathrm{R} / /}$ by simple observations using laser sheets at the channel mid-height. They define $\mathrm{L}_{\mathrm{R} / /}$ as the distance from the entrance to a point where all the boundaries between the longitudinal rolls are visible in the laser sheet. Pabiou ${ }^{36}$ gives the following correlation for $\mathrm{L}_{\mathrm{R} / /}$, valid for $87 \leq \mathrm{Re} \leq 310$ and $4500 \leq \mathrm{Ra} \leq 9900$,

$$
\mathrm{L}_{\mathrm{R} / /}=1.68[(\mathrm{Ra}-1708) / 1708]^{-0.67} \mathrm{Re}^{0.79} \text {. }
$$

These correlations are graphically presented for $\mathrm{Re}=50,100,150$, and 200 in Fig. 5 together with our results of $\mathrm{L}_{\mathrm{R} / /}$. In our case, $\mathrm{L}_{\mathrm{R} / /}$ is based on the averaged wall Nusselt numbers $\overline{\mathrm{Nu}}$ (see Eqs. (11) and (12)). It is defined as the distance from the entrance to a point where $\overline{\mathrm{Nu}}(\mathrm{x} ; \mathrm{z}=0)$

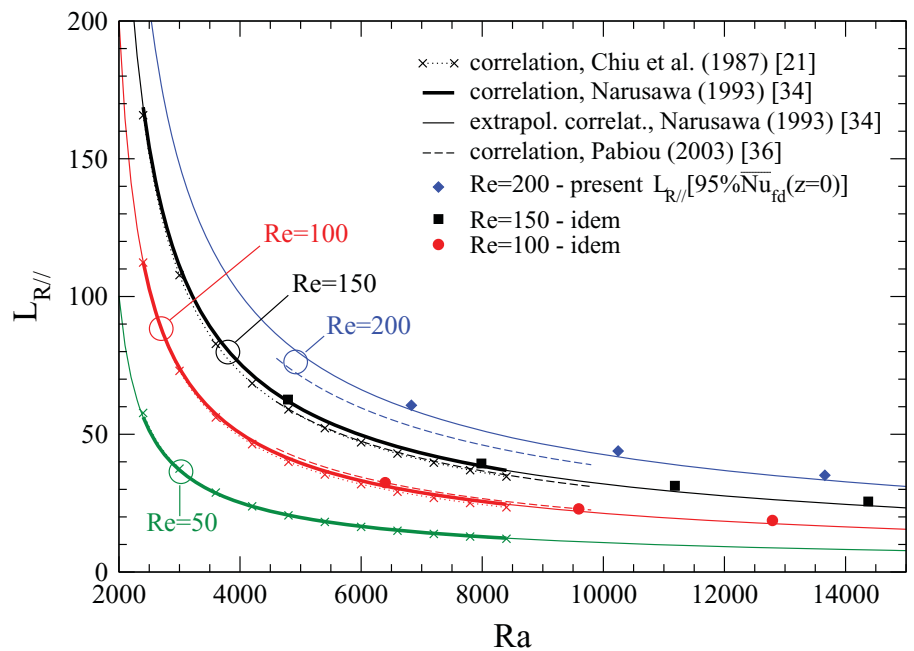

FIG. 5. Comparison of the correlations on the longitudinal roll growth length $\mathrm{L}_{\mathrm{R} / /}$ extracted from Refs. 21, 34, and 36 with the present numerical results of $\mathrm{L}_{\mathrm{R} / /}\left[95 \% \overline{\mathrm{Nu}}_{\mathrm{fd}}(\mathrm{z}=0)\right]$. The correlation established by Narusawa ${ }^{34}$ for $\mathrm{Re} \leq 120$ and $\mathrm{Ra}$ $\leq 8300$ (see main text) is extrapolated to $\mathrm{Re} \leq 200$ and $\mathrm{Ra} \leq 15000$ and is shown to fit the present results with a maximum $4 \%$ error. 


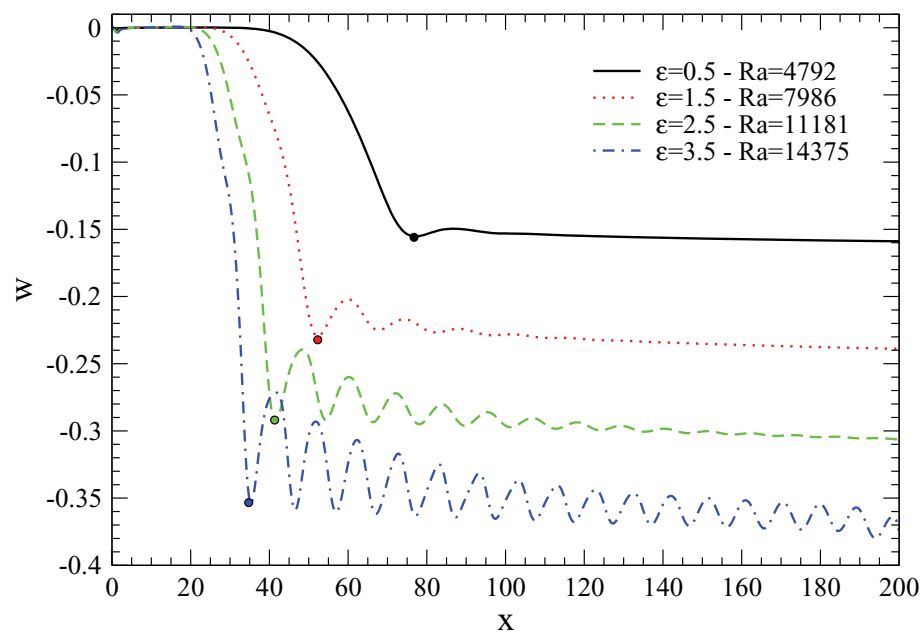

FIG. 6. Streamwise profiles of $\mathrm{w}(\mathrm{x})$ at $(\mathrm{y} ; \mathrm{z})=(\mathrm{B} / 2 ; 0.5)$ at $\mathrm{Re}=150$ for four Ra values. The filled circles on the profiles indicate the location of $\mathrm{L}_{\mathrm{R} / /}\left[\mathrm{w}_{\min }(\mathrm{y}=\mathrm{B} / 2 ; \mathrm{z}=0.5)\right]$.

reaches $95 \%$ of $\overline{\mathrm{Nu}}_{\mathrm{fd}}(\mathrm{z}=0)$ in the fully developed region. This growth length is denoted as $\mathrm{L}_{\mathrm{R} / /[95 \%}$ $\left.\overline{\mathrm{Nu}}_{\mathrm{fd}}(\mathrm{z}=0)\right]$ in the following. We have adopted this definition because it is easier to compute numerically than Chiu and Rosenberger's definition ${ }^{21}$ and because Narusawa ${ }^{34}$ showed that both definitions, based on the spanwise u profile or $\overline{\mathrm{Nu}}$, allow computing nearly the same growth lengths. In Fig. 5, it appears that the present results are in good agreement with the correlation (14) established by Narusawa. ${ }^{34}$ Furthermore, when this correlation is extrapolated to $\mathrm{Re} \leq 200$ and $\mathrm{Ra} \leq 15000$, it fits the present results with a maximum $4 \%$ error. It can, therefore, be considered that the correlation (14) is valid for $15 \leq \operatorname{Re} \leq 200$ and $2470<\mathrm{Ra} \leq 15000$.

However, as can be seen below, all the growth lengths defined above are too short compared to what should be called the growth length of fully established longitudinal rolls. Indeed, Figs. 6 and 7 present the streamwise profiles of $\mathrm{w}$ velocity at $\mathrm{y}=\mathrm{B} / 2$ and $\mathrm{z}=0.5, \mathrm{Nu}(\mathrm{x} ; \mathrm{y}=\mathrm{B} / 2 ; \mathrm{z}$ $=0)$ and $\overline{\mathrm{Nu}}(\mathrm{x}, \mathrm{z}=0)$, at $\mathrm{Re}=150$ and for four Ra values. Downstream the forced convec-

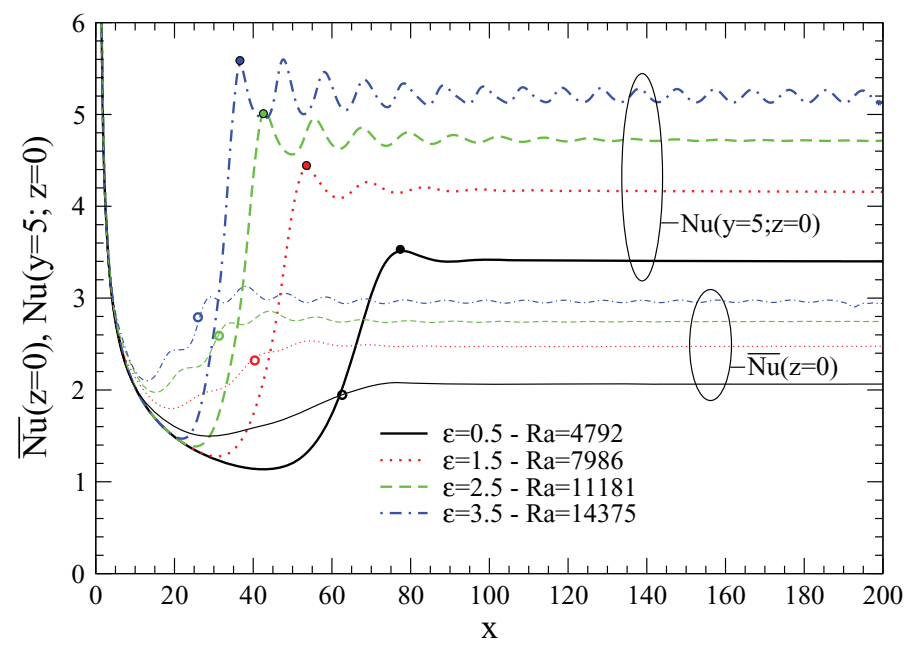

FIG. 7. Streamwise profiles of $\mathrm{Nu}(\mathrm{x})$ at $(\mathrm{y} ; \mathrm{z})=(\mathrm{B} / 2 ; 0)$ and $\overline{\mathrm{Nu}}(\mathrm{x})$ at $\mathrm{z}=0$, at $\mathrm{Re}=150$ for four Ra values. The filled circles on the profiles indicate the location of $\mathrm{L}_{\mathrm{R} / /}\left[\mathrm{Nu}_{\max }(\mathrm{y}=\mathrm{B} / 2 ; \mathrm{z}=0)\right]$ and the empty circles indicate that of $\mathrm{L}_{\mathrm{R} /[}[95 \%$ $\left.\overline{\mathrm{Nu}}_{\mathrm{fd}}(\mathrm{z}=0)\right]$. 


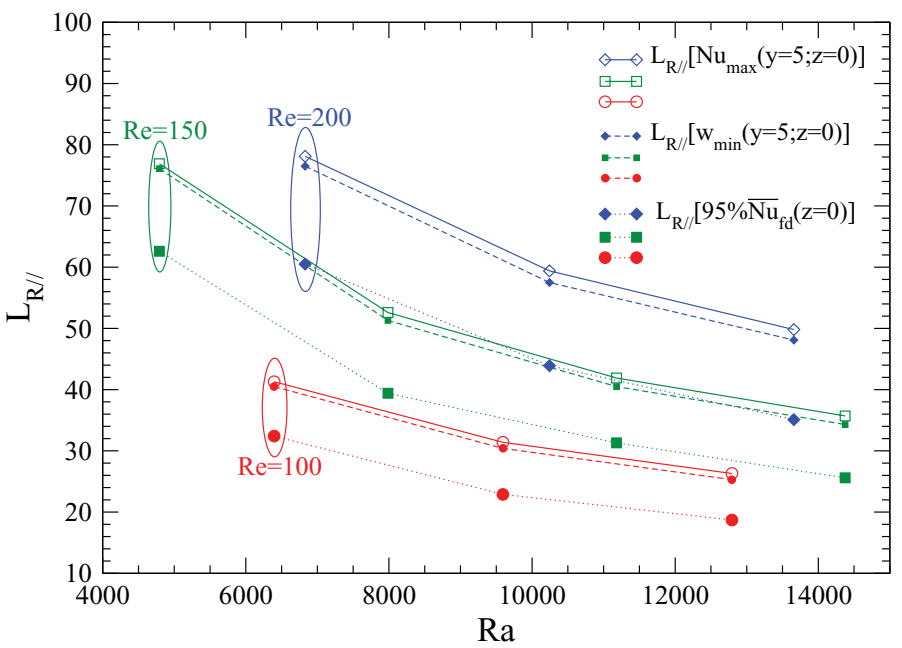

FIG. 8. Comparison of the three different growth lengths defined for longitudinal rolls in the present study, for the ten couples of Re-Ra investigated.

tion entrance zone, all the profiles present a first local extremum indicated by a small circle in Figs. 6 and 7. These local extrema are eventually followed by damped modulations (a saturated modulation is observed at the highest Rayleigh number). The streamwise coordinate, $\mathrm{x}$, of the first local minimum of $\mathrm{w}(\mathrm{x} ; \mathrm{y}=\mathrm{B} / 2 ; \mathrm{z}=0.5)$ and of the maximum of $\mathrm{Nu}(\mathrm{x} ; \mathrm{y}=\mathrm{B} / 2 ; \mathrm{z}=0)$ allow us to define two new growth lengths for the longitudinal rolls. They are denoted by $\mathrm{L}_{\mathrm{R} / /}\left[\mathrm{w}_{\min }(\mathrm{y}=5 ; \mathrm{z}\right.$ $=0.5)]$ and $\mathrm{L}_{\mathrm{R} /[}\left[\mathrm{Nu}_{\max }(\mathrm{y}=5 ; \mathrm{z}=0)\right]$, respectively. The different growth lengths are compared in Fig. 8 for the ten couples of Re-Ra investigated (see also Fig. 3 in the case: $\operatorname{Re}=150, \operatorname{Ra}=11181$ ). It appears that $\mathrm{L}_{\mathrm{R} / /}\left[\mathrm{Nu}_{\max }(\mathrm{y}=5 ; \mathrm{z}=0)\right]$ is slightly longer than $\mathrm{L}_{\mathrm{R} / /}\left[\mathrm{w}_{\min }(\mathrm{y}=5 ; \mathrm{z}=0.5)\right]$, but both of them are much longer than $\mathrm{L}_{\mathrm{R} / /[}\left[95 \% \overline{\mathrm{Nu}}_{\mathrm{fd}}(\mathrm{z}=0)\right]$. The relative difference between $\mathrm{L}_{\mathrm{R} / /}\left[\mathrm{Nu}_{\max }(\mathrm{y}\right.$ $=5 ; \mathrm{z}=0)]$ and $\mathrm{L}_{\mathrm{R} / /}\left[95 \% \overline{\mathrm{Nu}}_{\mathrm{fd}}(\mathrm{z}=0)\right]$ varies between $24 \%$ and $35 \%$ for the ten simulated cases. As a consequence, we would advise to henceforth use a quantity similar to $L_{R / /}\left[w_{\min }(y=B / 2\right.$; $\mathrm{z}=0.5)]$ to define the appearance length of fully developed longitudinal rolls in PRB flows, because it seems more appropriate and because the local extremum of the vertical velocity component on the channel axis can be easily accessed both numerically and experimentally (by Particle Image Velocimetry or LDV). As the $w$ minimum does not exist or is difficult to detect for $\mathrm{Ra}<4000$ (see $\mathrm{w}$ profile at $\varepsilon=0.5$ and $\mathrm{Ra}=4792$ in Fig. 6), a criterion based on $95 \%$ of the fully developed $\mathrm{w}$ velocity on channel axis could then be used. Using a correlation similar to Eqs. (13)-(15), we finally obtain

$$
\mathrm{L}_{\mathrm{R} / /}\left[\mathrm{W}_{\min }(\mathrm{y}=\mathrm{B} / 2 ; \mathrm{z}=0.5)\right]=0.578[(\mathrm{Ra}-1708) / 1708]^{-0.41} \mathrm{Re}^{0.922} .
$$

This correlation is valid for $100 \leq \mathrm{Re} \leq 200$ and $4500 \leq \mathrm{Ra} \leq 15000$ and it fits the present numerical results with a maximum $3 \%$ error.

The averaged Nusselt number $\overline{\mathrm{Nu}}_{\mathrm{fd}}$ of fully developed longitudinal roll flows is computed according to Eq. (12). In this equation, $\overline{\mathrm{Nu}}(\mathrm{x} ; \mathrm{z}=0,1)$ tends to a constant, independent of $\mathrm{x}$, for a given fully established longitudinal or wavy roll flow (see Fig. 7). Thus, depending on Re and Ra values, different values of $\mathrm{L}_{\mathrm{e}}^{+}$have been chosen so that Eq. (12) provides $\overline{\mathrm{Nu}}_{\mathrm{fd}}$ independent of $\mathrm{L}_{\mathrm{e}}{ }^{+}$. The values of $\mathrm{L}_{\mathrm{e}}{ }^{+}$used, larger than $\mathrm{L}_{\mathrm{R} / /}\left[\mathrm{Nu}_{\max }(\mathrm{y}=5 ; \mathrm{z}=0)\right]$ in all cases, are the following: 60 $\leq \mathrm{L}_{\mathrm{e}}{ }^{+} \leq 80$ for $\mathrm{Re}=100,100 \leq \mathrm{L}_{\mathrm{e}}{ }^{+} \leq 110$ for $\mathrm{Re}=150$, and $100 \leq \mathrm{L}_{\mathrm{e}}{ }^{+} \leq 120$ for $\mathrm{Re}=200$. The $\overline{\mathrm{Nu}}_{\mathrm{fd}}$ values computed on the top and bottom plates of the channel are nearly equal: it has been checked that the relative difference $\left[\overline{\mathrm{Nu}}_{\mathrm{fd}}(\mathrm{z}=0)-\overline{\mathrm{Nu}}_{\mathrm{fd}}(\mathrm{z}=1)\right] / \overline{\mathrm{Nu}}_{\mathrm{fd}}(\mathrm{z}=0)$ is approximately equal to $+0.1 \%$ in the simulated cases.

In Fig. 9, the present $\overline{\mathrm{Nu}}_{\mathrm{fd}}$ values are compared to the correlations established in air by Ostrach and $\mathrm{Kamotani}^{24}$ through experiments at $18 \leq \mathrm{B}<36,10 \leq \mathrm{Re} \leq 100$, and $100 \leq \mathrm{Ra} \leq 13500$ 


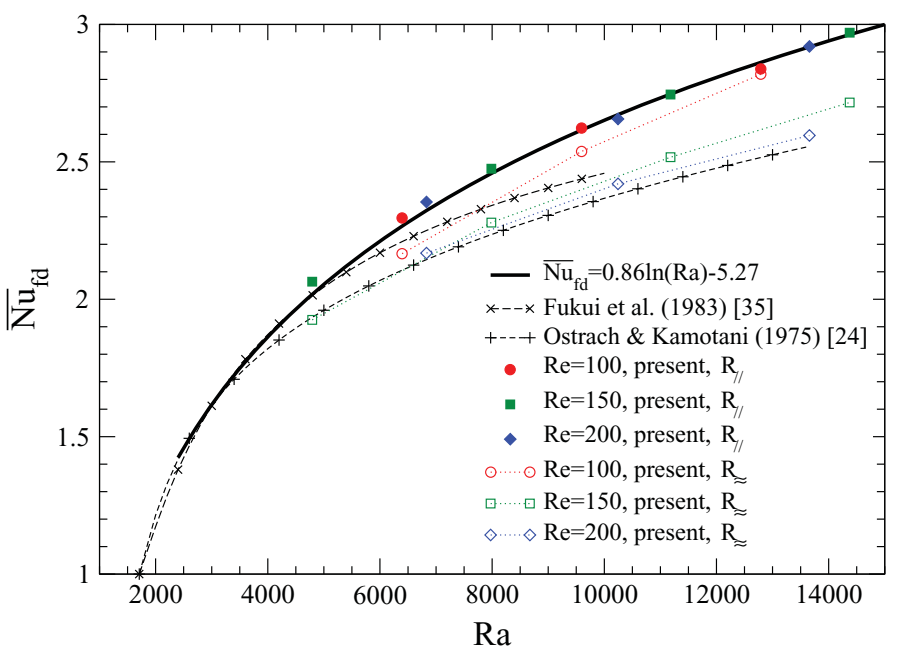

FIG. 9. Comparison of averaged Nusselt number $\overline{\mathrm{Nu}}_{\mathrm{fd}}$ in fully developed longitudinal roll flows (noted by $\mathrm{R} / /$ ) with the correlations extracted from Refs. 24 and 35. The continuous bold line is the correlation Eq. (17) valid for $2500 \leq \mathrm{Ra} \leq 15$ 000. Numerical results of $\overline{\mathrm{Nu}}_{\mathrm{fd}}$ for wavy chaotic rolls (noted by $\mathrm{R} \approx$ ) are also indicated.

and by Fukui et al. ${ }^{35}$ through finite difference numerical simulations at $\mathrm{B}=20,17 \leq \mathrm{Re} \leq 80$, and $\mathrm{Ra} \leq 9300$. It is well known that $\overline{\mathrm{Nu}}_{\mathrm{fd}}$ is independent of Re because the flow structure of the fully established longitudinal rolls near the top and bottom plates are not modified by Re. The present values agree well with the results of Fukui et al. only for $\mathrm{Ra}<6500$ and are higher for $\mathrm{Ra}>6500$. This is probably due to the grid inaccuracy in z-direction in Ref. 35: only 21 nodes have been used and they are probably insufficient for the highest Rayleigh numbers. A $\overline{\mathrm{Nu}}_{\mathrm{fd}}$ correlation, which is valid for $2500 \leq \mathrm{Ra} \leq 15000$ (Fig. 9) and fits within a 3\% relative error both the present values and the values of Fukui et al. for $\mathrm{Ra}<6500,{ }^{35}$ is

$$
\overline{\mathrm{Nu}}_{\mathrm{fd}}\left(\mathrm{R}_{/ /}\right)=0.86 \ln (\mathrm{Ra})-5.27 .
$$

Experimental $\overline{\mathrm{Nu}}_{\mathrm{fd}}$ results obtained by Ostrach and Kamotani ${ }^{24}$ are estimated to be measured with a $\pm 10 \%$ error. However, these values are up to $15 \%$ smaller than the numerical results for $\mathrm{Ra}>10^{4}$; this is also the case for the numerical solutions of Ref. 37 (included in Ref. 24). In these simulations, longitudinal rolls are steady whatever Re and Ra are while, in the experiments, longitudinal rolls become unstable and unsteady for $\mathrm{Ra}>8000$ and the magnitude of temperature fluctuations increases as Ra increases. Referring to Fig. 1, the unsteady experimental behavior is clearly due to the oscillating rolls observed at $\mathrm{Ra}>8000$ and $\mathrm{Re}<100$. On the other hand, in the numerical simulations, the longitudinal rolls remain steady because the governing equations are parabolized in Refs. 35 and 37 (the streamwise diffusion is neglected in the momentum and energy equations) and because Reynolds number is higher than 100 in the present work: longitudinal rolls remain stable if no excitation is introduced in the channel (see Fig. 1).

The interesting observation from Fig. 9 is that, when longitudinal rolls are excited and replaced by wavy rolls, in particular, at Re $=150$ and 200 (see Sec. V E and Fig. 23), the present results of $\overline{\mathrm{Nu}}_{\mathrm{fd}}$ precisely tend to the experimental measurements of Ostrach and Kamotani. ${ }^{24}$ In fact, $\overline{\mathrm{Nu}}_{\mathrm{fd}}$ decreases when longitudinal rolls become oscillating or wavy because a better flow mixing is operated by the spanwise oscillations in the channel core. This is brought to light in Figs. 10 and 11 that present a $3 \mathrm{D}$ distribution of the instantaneous temperature field in a wavy roll flow and a comparison of mean temperature vertical profiles in fully established longitudinal and wavy rolls, respectively. In Fig. 11, the mean temperature gradients at the top and bottom walls are clearly smaller in the presence of wavy rolls. Furthermore, the well-known reverse temperature gradients ${ }^{24}$ observed in the temperature, vertical profiles of the longitudinal rolls at high Rayleigh number can vanish in the presence of wavy rolls: indeed, in Fig. 11, the sign of the mean temperature gradient changes at $\mathrm{z}$ 


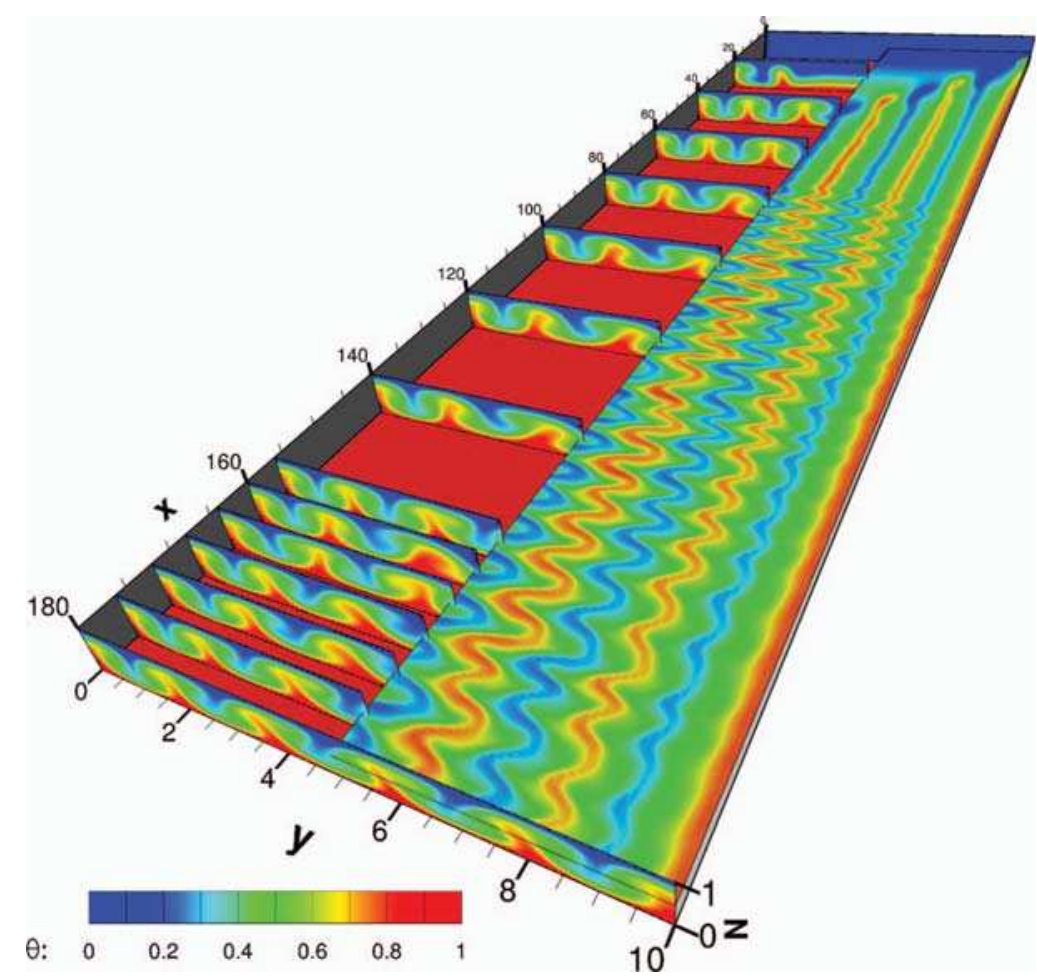

FIG. 10. Space distribution of instantaneous temperature field in the wavy roll flow at $\mathrm{Re}=150, \varepsilon=2.5$, and $\mathrm{A}_{\mathrm{exc}}=0.1$ (case 6 of Table II). The left part of the figure displays temperature field in 14 vertical half-planes; the right part shows temperature field in the horizontal half-plane at $\mathrm{z}=0.5$ (red and blue colors show hot ascending and cold descending air, respectively)

$=0.36$ and $\mathrm{z}=0.64$ for the longitudinal rolls, while it is negative whatever $\mathrm{z}$ for the wavy rolls. This demonstrates that as the spanwise mixing due to wavy rolls increases, the bulk temperature is homogenized and the temperature gradients near the bottom and top plates are also homogenized and decrease.

In Fig. 9, $\overline{\mathrm{Nu}}_{\mathrm{fd}}$ is a function of $\mathrm{Ra}$ (or $\varepsilon$ ) and $\mathrm{Re}$ for the wavy roll flows because the magnitude of their spanwise oscillations depends on these two parameters (see Fig. 23). To correlate the wavy

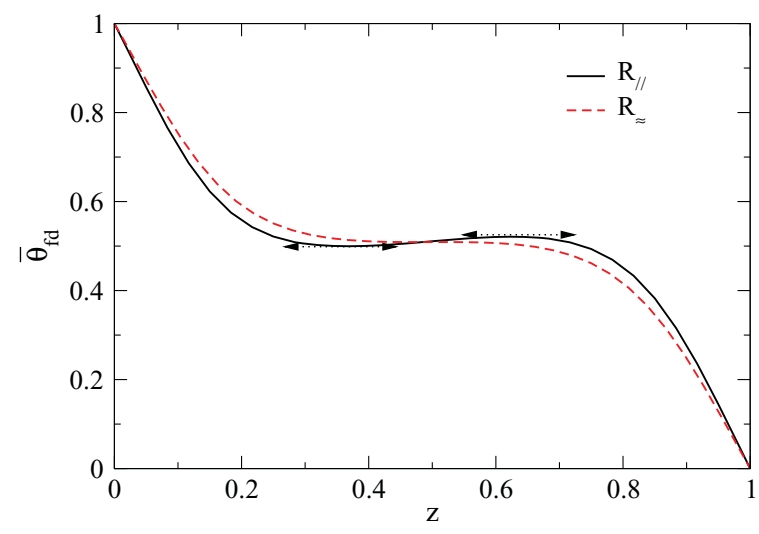

FIG. 11. Vertical profiles of the mean temperature in the horizontal planes of the fully developed zones for the longitudinal $\left(\mathrm{R}_{/ /}\right)$and wavy $(\mathrm{R} \approx)$ roll flows at $\mathrm{Re}=200, \varepsilon=3$, and $\mathrm{A}_{\mathrm{exc}}=0.1$ (case 13 of Table II). The arrows mark the horizontal tangents at $\mathrm{z}=0.36$ and $\mathrm{z}=0.64$ in the longitudinal roll temperature profile. 

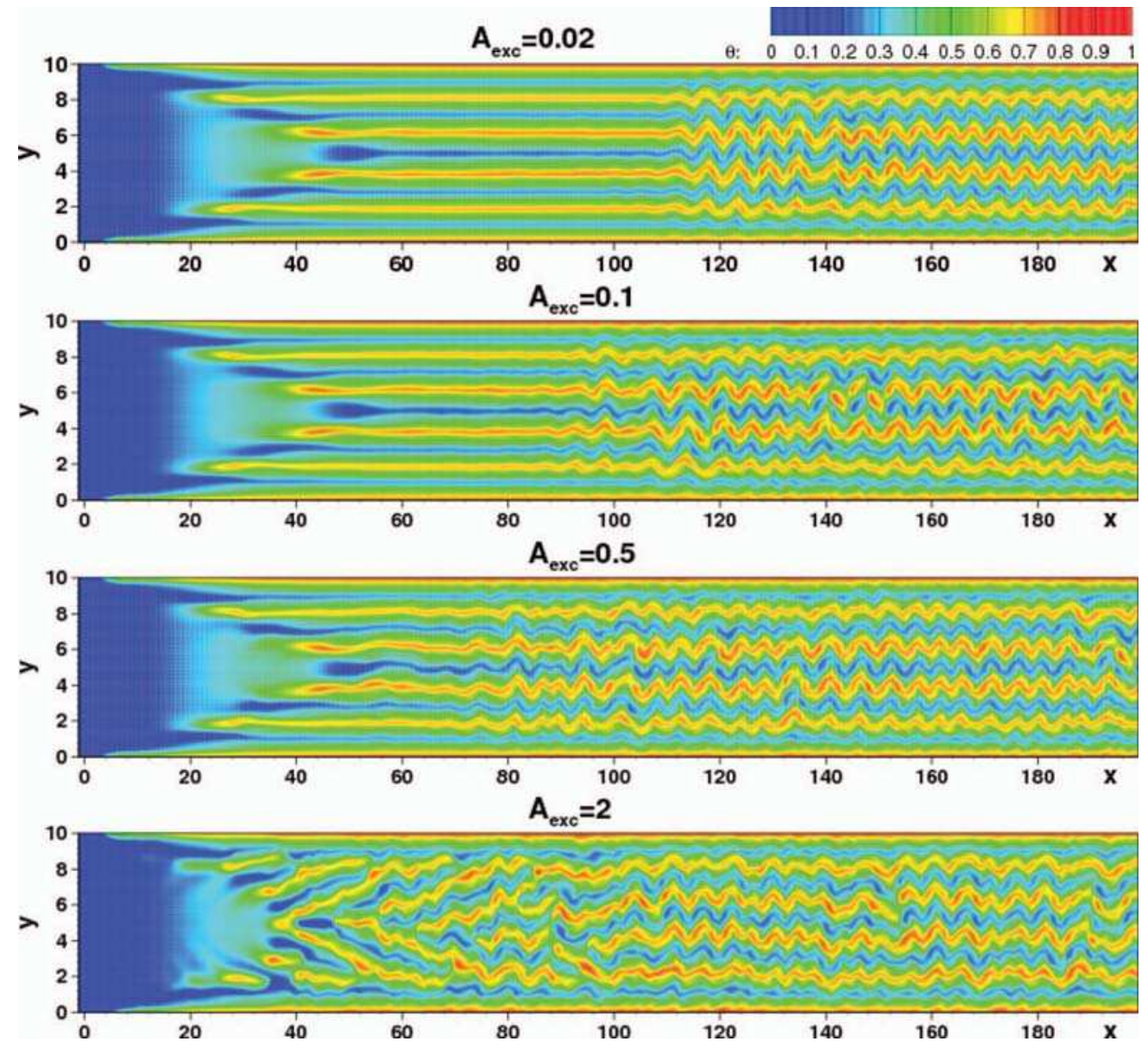

FIG. 12. Instantaneous temperature field at $\mathrm{z}=0.5$ in flows of ten wavy rolls in the fully developed zone, resulting from inlet random excitations of magnitudes $\mathrm{A}_{\mathrm{exc}}=0.02,0.1,0.5$, and 2 , at $\mathrm{Re}=200$ and $\varepsilon=2$ (cases $9-12$ of Table II). The color map is the same for the four pictures.

roll $\overline{\mathrm{Nu}}_{\mathrm{fd}}$ values, the following quadratic response surface was found:

$$
\overline{\mathrm{Nu}}_{\mathrm{fd}}\left(\mathrm{R}_{\approx}\right)=\left(2172.2-7.145 \mathrm{Re}+591.9 \varepsilon+0.0276 \mathrm{Re}^{2}-39.5 \varepsilon^{2}-1.125 \varepsilon \mathrm{Re}\right) \times 10^{-3} .
$$

It is valid for $100 \leq \mathrm{Re} \leq 200$ and $4500 \leq \mathrm{Ra} \leq 15000(0.5 \leq \varepsilon \leq 3.5)$ and it fits the present numerical results within a $0.6 \%$ relative error.

\section{Influence of excitation amplitude on wavy rolls}

The influence of the inlet excitation amplitude, $\mathrm{A}_{\text {exc }}$, on the wavy roll development, is investigated here at $\mathrm{Re}=200$ and $\mathrm{Ra}=10244(\varepsilon=2)$ for $\mathrm{A}_{\mathrm{exc}}=0.02,0.1,0.5$, and 2 (cases 9-12 of Table II). Figure 12 displays temperature field at $\mathrm{z}=0.5$ obtained for the four amplitude values. Air flows from left to right. Red and yellow colors correspond to upwards hot air between two counter-rotating rolls and blue color to entering and downwards cold air. Whatever $\mathrm{A}_{\mathrm{exc}}$ is, five pairs of thermoconvective rolls develop in the channel.

For $\mathrm{A}_{\mathrm{exc}}=0.02,0.1$, and 0.5 , the space development of the wavy rolls qualitatively occurs according to the same scenario which will be described using the case $A_{\text {exc }}=0.1$. Typical axial evolution of the Fourier spectra of spanwise velocity v(t) obtained with $A_{\text {exc }}=0.1$ is shown in Fig. 13. In the upstream part of the channel (for $x<65$ ), ten longitudinal rolls that develop from the lateral boundaries go on forming the forced convection triangular zone described in Sec. V C. 

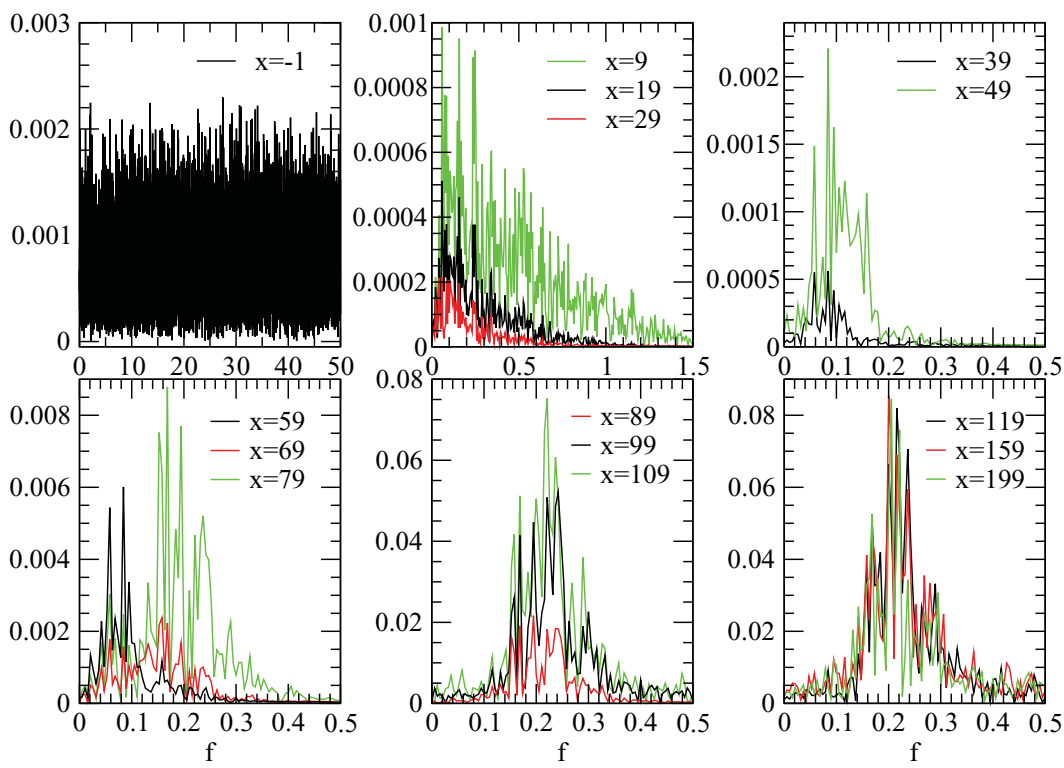

FIG. 13. Fourier spectra of $\mathrm{v}(\mathrm{t})$ at different $\mathrm{x}$ coordinates along channel axis $(\mathrm{y}, \mathrm{z})=(5,0.5)$ for $\operatorname{Re}=200, \varepsilon=2$, and $\mathrm{A}_{\mathrm{exc}}$ $=0.1$. The spectrum at $\mathrm{x}=-1$ corresponds to the inlet white noise.

Fourier spectrum magnitude of $\mathrm{v}(\mathrm{t})$ at $(\mathrm{y}, \mathrm{z})=(5,0.5)$ keeps decreasing up to $\mathrm{x}=30$ and the range of amplified modes shrinks to reach $0 \leq \mathrm{f} \leq 0.16$ (see Fig. 13). For $30<\mathrm{x} \leq 65$, the magnitude of these low frequency modes keeps growing. But, at about $x=69$, it suddenly decreases and it is the higher frequency modes $(0.15 \leq \mathrm{f} \leq 0.25)$ that start increasing and reach the saturation at $\mathrm{x}=120$. In the zone of $65<\mathrm{x}<120$, longitudinal rolls become more and more wavy (see Fig. 12). Further downstream (for $120 \leq \mathrm{x} \leq 199$ at $\mathrm{A}_{\mathrm{exc}}=0.1$ ), the Fourier spectra, in particular their most amplified frequency $\mathrm{f}^{\circ}=0.205$, and the averaged amplitude of wavy roll oscillations no longer vary with $\mathrm{x}$ (see below): the wavy roll flow is fully developed.

The behavior just described is very similar to what was predicted by Deissler ${ }^{13,14}$ from the 1D Ginzburg-Landau model. It is shown that, when a white noise is introduced at channel inlet in a convectively unstable flow, it is selectively and spatially amplified: this results in spatially growing waves that saturate due to nonlinear effects and form a dynamic structure sufficiently far from inlet. In the $1 \mathrm{D}$ model, the nonlinear structure is generally coherent in its first portion. But, if the first portion is also convectively unstable, it breaks up downstream, due to the irregularities in the flow, to form a chaotic flow uncorrelated from the inlet noise. Unfortunately, it was impossible in the present 3D nonlinear numerical simulations to check if the time signals downstream the channel are correlated with the inlet noise. In fact, to get reliable cross correlations between two time signals, one recorded at inlet and the other one downstream, long time integrations, much longer than what was permissible on the used super computer, are needed. We can just observe from Fig. 12, for $\mathrm{A}_{\mathrm{exc}}$ $=0.02,0.1$, and 0.5 , that wavy rolls are maintained in the whole downstream part of the channel.

The flow behavior at $A_{\mathrm{exc}}=2$ is slightly different. The excitation magnitude imposed on $\mathrm{v}(\mathrm{t})$ at inlet is very important since it is equal to twice the mean streamwise velocity. Due to the important white noise introduced, the initial longitudinal rolls are no longer present: they break up just downstream the inlet to form V-shaped patterns (see Fig. 12). Nevertheless, a chaotic wavy roll flow develops for $\mathrm{x}>100$. The way the amplified modes are selected is also slightly different: for $\mathrm{x}<30$ and $\mathrm{x}>110$ the same scenario as in Fig. 13 is observed for $\mathrm{A}_{\mathrm{exc}}=2$; the difference in Fourier spectra is observed for $30 \leq \mathrm{x} \leq 110$. For $\mathrm{A}_{\mathrm{exc}}=2$, the $\mathrm{v}(\mathrm{t})$ Fourier spectra (not shown here) have a wider amplified frequency range, $0<\mathrm{f}<0.5$, for $30 \leq \mathrm{x}<65$ and for $65<\mathrm{x}<110$ only the magnitude of the modes $0.1<\mathrm{f}<0.3$ goes on increasing. As shown in Fig. 14, Fourier spectrum in the fully developed zone at $\mathrm{A}_{\mathrm{exc}}=2$ is similar to those obtained at $\mathrm{A}_{\mathrm{exc}}=0.02,0.1$, and 0.5 , except 


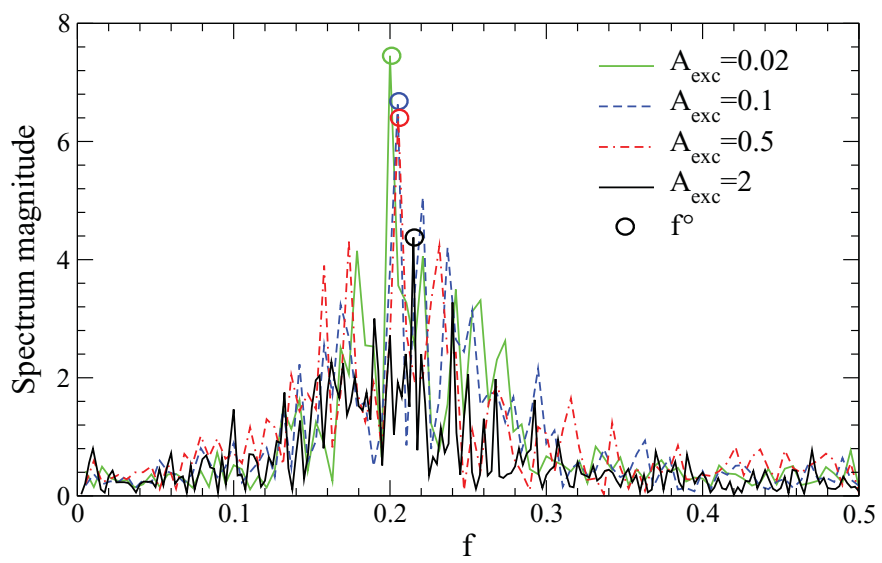

FIG. 14. Fourier spectra of $\mathrm{v}(\mathrm{t})$ at $(\mathrm{x}, \mathrm{y}, \mathrm{z})=(175,5,0.5)$ obtained with four excitation amplitudes for $\operatorname{Re}=200$ and $\varepsilon=2$. The frequency of the highest magnitude, $\mathrm{f}^{\circ}$, in each spectrum is indicated by a circle.

for its lower magnitude. The amplified modes of the four spectra are in the range $0.1 \leq \mathrm{f} \leq 0.32$ with a dominant frequency approximately equal to $\mathrm{f}^{\circ} \approx 0.21$.

In fact most of the characteristics of fully developed wavy rolls presented in Fig. 12 are independent, or quasi-independent, of the inlet excitation magnitude. For instance, Fig. 15 presents the wave number, $\mathrm{k}_{\mathrm{x}}{ }^{\circ}$, and phase velocity, $\mathrm{c}^{\circ}=2 \pi \mathrm{f}^{\circ} / \mathrm{k}_{\mathrm{x}}{ }^{\circ}$, associated with the most amplified mode, $\mathrm{f}^{\circ}$, in the $\mathrm{v}(\mathrm{t})$ Fourier spectra, as a function of $\mathrm{A}_{\mathrm{exc}}$. It appears that $\mathrm{k}_{\mathrm{x}}{ }^{\circ}=1.12 \pm 0.07, \mathrm{f}^{\circ}=0.208$ \pm 0.012 and $\mathrm{c}^{\circ}=1.162 \pm 0.04$ for $\mathrm{A}_{\mathrm{exc}}$ varying from 0.02 to 2 . Thus the relative variations of $\mathrm{k}_{\mathrm{x}}{ }^{\circ}$, $\mathrm{f}^{\circ}$, and $\mathrm{c}^{\circ}$ in this large $\mathrm{A}_{\mathrm{exc}}$ range are at maximum equal to $7 \%, 6 \%$, and $4 \%$, respectively. Note that, in Fig. 15 , the $\mathrm{k}_{\mathrm{x}}{ }^{\circ}$ values are computed from a mean on 13-20 wavelengths (depending on $\mathrm{A}_{\mathrm{exc}}$ ) and the error bars on $\mathrm{k}_{\mathrm{x}}{ }^{\circ}$ are equal to three times the standard deviation of $\mathrm{k}_{\mathrm{x}}{ }^{\circ}$. The error bars on $\mathrm{f}^{\circ}$ equal to $\pm \Delta \mathrm{f}= \pm 4 \times 10^{-3}$ are defined in Sec. $\mathrm{V}$ B and the error bars on $\mathrm{c}^{\circ}$ are deduced from those on $\mathrm{k}_{\mathrm{x}}{ }^{\circ}$ and $\mathrm{f}^{\circ}$ since $\mathrm{c}^{\circ}=2 \pi \mathrm{f}^{\circ} / \mathrm{k}_{\mathrm{x}}{ }^{\circ}$.

Similarly, Fig. 16 shows that $\overline{\mathrm{Nu}}_{\mathrm{fd}}$ values on the top and bottom plates in the fully developed zone also remain nearly constant (they decrease very slightly with $\left.\mathrm{A}_{\mathrm{exc}}\right): \overline{\mathrm{Nu}}_{\mathrm{fd}}(\mathrm{z}=0) \approx \overline{\mathrm{Nu}}_{\mathrm{fd}}(\mathrm{z}$ $=1) \approx 2.41 \pm 0.01$ whatever $\mathrm{A}_{\mathrm{exc}}$ is. Here, $\overline{\mathrm{Nu}}_{\mathrm{fd}}$ is computed using Eq. (12) with $\mathrm{L}_{\mathrm{e}}{ }^{+}=\mathrm{L}_{V_{\mathrm{s}}}+10$ where $\mathrm{L}_{\mathrm{Vs}}$ is defined below.

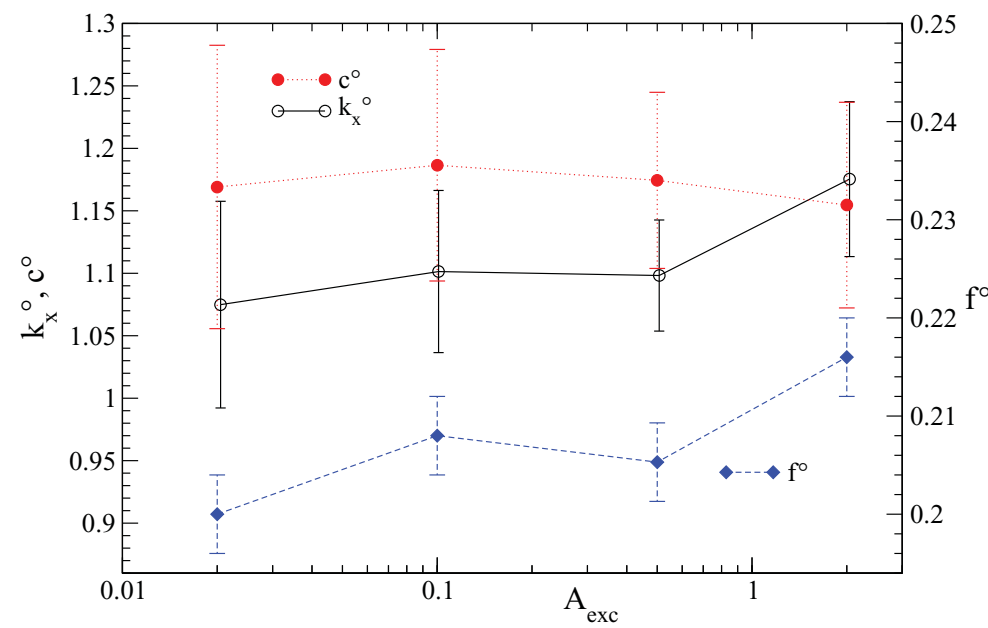

FIG. 15. Wave number, $\mathrm{k}_{\mathrm{x}}^{\circ}$, frequency, $\mathrm{f}^{\circ}$, and phase velocity, $\mathrm{c}^{\circ}=2 \pi \mathrm{f}^{\circ} / \mathrm{k}_{\mathrm{x}}^{\circ}$, of the most amplified mode in the fully developed wavy roll flows of Fig. 12, with respect to $\mathrm{A}_{\mathrm{exc}}$. 


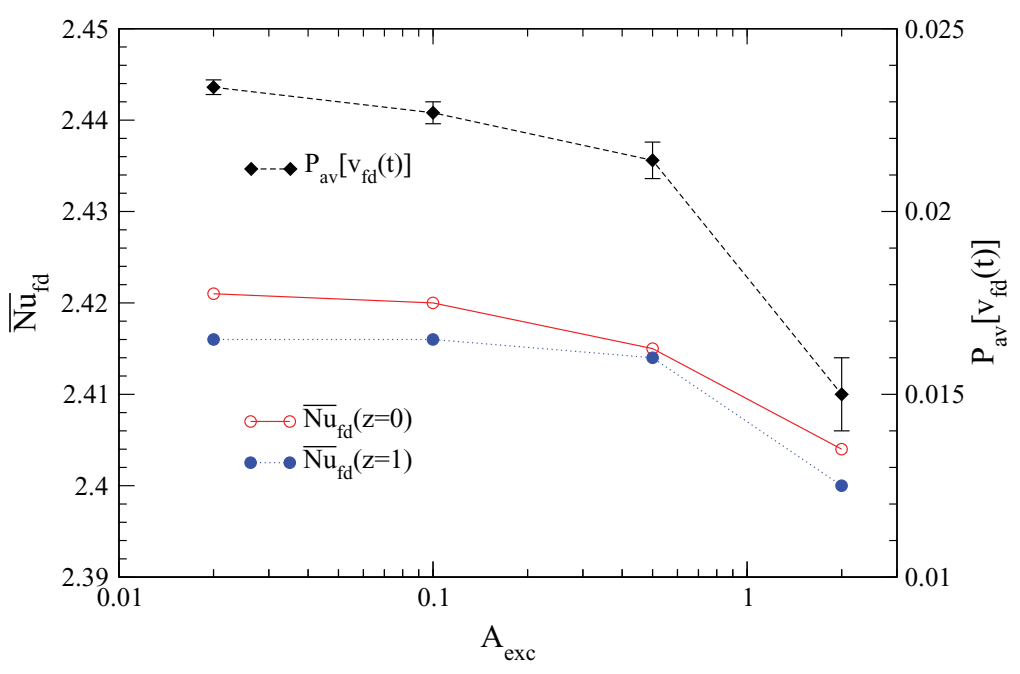

FIG. 16. Nusselt number and averaged power of the $v(t)$ spectra in the fully developed wavy roll zone with respect to $A_{\text {exc }}$ for the four flows of Fig. 12 .

The above observations on the wavy roll flows at $(\operatorname{Re}, \varepsilon)=(200,2)$ (and also at the other Re- $\varepsilon$ couples in Table II) are in accordance with the fact that the wavy patterns are a secondary instability of the basic Poiseuille flow and a convective instability of the longitudinal rolls. In other words, the longitudinal rolls are convectively unstable towards the wavy roll-shaped secondary instability. 8,9 The above observations also hint that wavy rolls are absolutely stable vis-à-vis tertiary instabilities of PRB flows. Indeed, if wavy rolls were convectively unstable towards these tertiary instabilities, the remaining noise injected at inlet and still present in the flow would have probably been sufficient to make another pattern type appear in the channel downstream part. This phenomenon was studied using a 1D Ginzburg-Landau model by Deissler. ${ }^{13,14}$ However, such a phenomenon has never been observed in the present numerical simulations, even with much longer channels (with $\mathrm{A}=350$, for example). This is the reason why in the present study it is possible to use an inlet white noise to analyze fully developed wavy rolls.

It has been mentioned in Fig. 14 that the magnitude of the most amplified mode of wavy rolls in fully developed zone decreases as $A_{\text {exc }}$ increases. In fact, the averaged power of the whole $v(t)$ spectrum (or signal) in the fully developed zone, noted $\mathrm{P}_{\mathrm{av}}\left(\mathrm{v}_{\mathrm{fd}}(\mathrm{t})\right.$ ), decreases as $\mathrm{A}_{\text {exc }}$ increases, in particular when $A_{\text {exc }}$ is increased from 0.5 to 2 (cf. Fig. 16). This spectrum total averaged power is computed by using the Plancherel/Parseval's theorem for discrete Fourier transform (DFT) as

$$
P_{a v}\left(V_{f d}(t)\right)=\sum_{i=1}^{N} v_{i}^{2}=\frac{1}{N} \sum_{k=1}^{N} \hat{v}_{k}^{2},
$$

where $\mathrm{N}$ is the sample number in the discrete signal $\mathrm{v}_{\mathrm{i}}(\mathrm{i}=1, \ldots, \mathrm{N})$ of $\mathrm{v}(\mathrm{t})$ recorded at $(\mathrm{x}, \mathrm{y}, \mathrm{z})$ $=(180,5,0.5)$ and $\hat{v}_{k}(k=1, \ldots, N)$ is the DFT of $v_{i}(i=1, \ldots, N) . \quad \mathrm{P}_{\mathrm{av}}\left(\mathrm{v}_{\mathrm{fd}}(\mathrm{t})\right)$ decreases with $\mathrm{A}_{\text {exc }}$ because the larger the inlet excitation magnitude is, the more important are the nonlinear interactions between all the excited modes of the spectrum and, as a consequence, the more important are the dissipative effects in the developing zone (for $\mathrm{x}<110$ ). At $\mathrm{A}_{\mathrm{exc}}=2$, the dissipative effects are very important because nonlinear interactions between a part of the modes injected in the inlet white noise are present everywhere in the channel, unlike at $\mathrm{A}_{\mathrm{exc}}=0.02,0.1$, and 0.5 . In these latter cases, a selection process of particular modes takes place in the entrance zone (where longitudinal rolls are visible in Fig. 12), followed by their linear growth, then their nonlinear growth and saturation. These particular amplified modes do not interact or less interact between themselves and the dissipative effects are much less present.

Figure 17 presents the envelopes of $\mathrm{v}(\mathrm{t})$ along the channel axis for the four flows displayed in Fig. 12. These envelopes give the maximum $\mathrm{v}$ values at each point of the channel axis throughout 


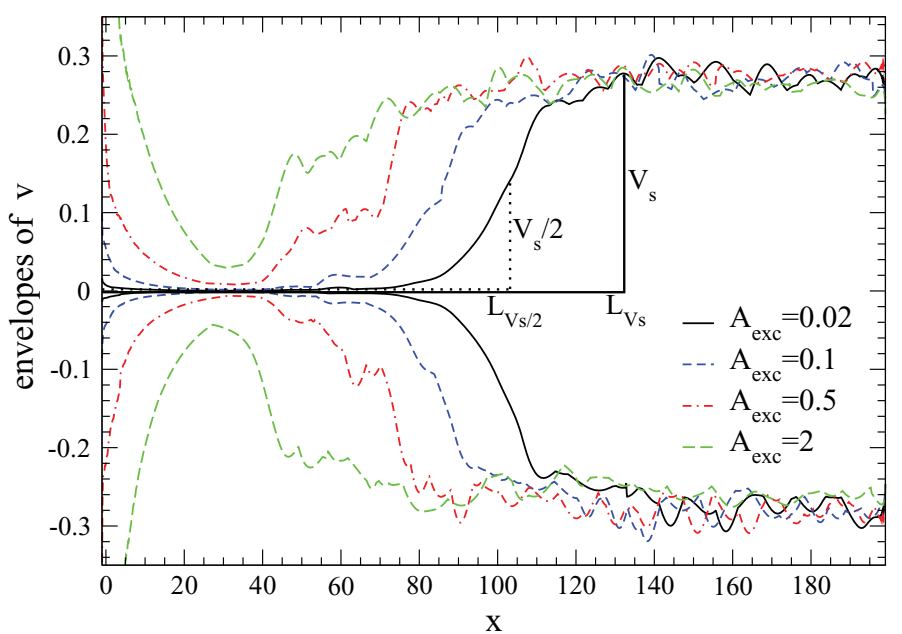

FIG. 17. Envelopes of $\mathrm{v}$ along the channel axis for the four flows of Fig. 12. The growth length $\mathrm{L}_{V_{s}}$ is represented by continuous lines and $\mathrm{L}_{\mathrm{V} / 2}$ by dotted lines for $\mathrm{A}_{\mathrm{exc}}=0.02$.

the entire third simulation step (cf. Sec. V B) in which wavy roll flows are fully established. The saturation amplitude of $\mathrm{v}$, denoted by $\mathrm{V}_{\mathrm{s}}$, is approximately constant whatever the excitation amplitude $A_{e x c}$ is. For each envelope, one can define two wavy roll growth lengths: $L_{V s}$ and $L_{V s / 2}$. $L_{V s}$ is the first $\mathrm{x}$ position at which the envelope reaches $\mathrm{V}_{\mathrm{s}}$, and $\mathrm{L}_{\mathrm{Vs} / 2}$ the $\mathrm{x}$ position of the half saturation amplitude $\mathrm{V}_{\mathrm{s}} / 2$ (see Fig. 17). Figure 18 shows that $\mathrm{L}_{\mathrm{Vs}}$ and $\mathrm{L}_{\mathrm{Vs} / 2}$ linearly decrease with the logarithm of $\mathrm{A}_{\mathrm{exc}}$, except for $\mathrm{L}_{\mathrm{Vs} / 2}$ at $\mathrm{A}_{\mathrm{exc}}=2$ due to very strong flow nonlinearity. The following regression laws are found for $\mathrm{L}_{\mathrm{Vs}}$ and $\mathrm{L}_{\mathrm{Vs} / 2}$ :

$$
\begin{aligned}
& \mathrm{L}_{\mathrm{Vs}}=90.646-26.091 \log \left(\mathrm{A}_{\mathrm{exc}}\right), \\
& \mathrm{L}_{\mathrm{Vs} / 2}=64.109-22.891 \log \left(\mathrm{A}_{\mathrm{exc}}\right) .
\end{aligned}
$$

Let us stress again that Eq. (21) is not valid at $A_{\text {exc }}=2$. Note that the same $\log \left(A_{\text {exc }}\right)$ dependence of the growth length was found in 2D numerical simulations by Müller et al. ${ }^{6}$ for the transverse roll shaped convective instability of PRB flows submitted to a permanent random excitation at channel inlet.

The influence of $\mathrm{A}_{\mathrm{exc}}$ on the spanwise displacement of the fully developed wavy rolls is studied now. In the present study, the vertical flow located between two longitudinal rolls or two wavy rolls

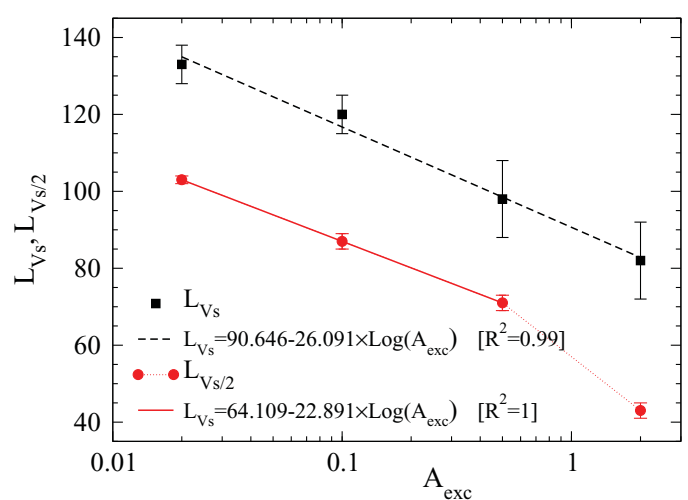

FIG. 18. Computed values and correlation laws of the wavy roll growth lengths $\mathrm{L}_{V_{s}}$ and $\mathrm{L}_{\mathrm{Vs}} / 2$ with respect to $\mathrm{A}_{\mathrm{exc}}$ for the four flows of Fig. 12. $\mathrm{R}^{2}$ is the correlation coefficient. 


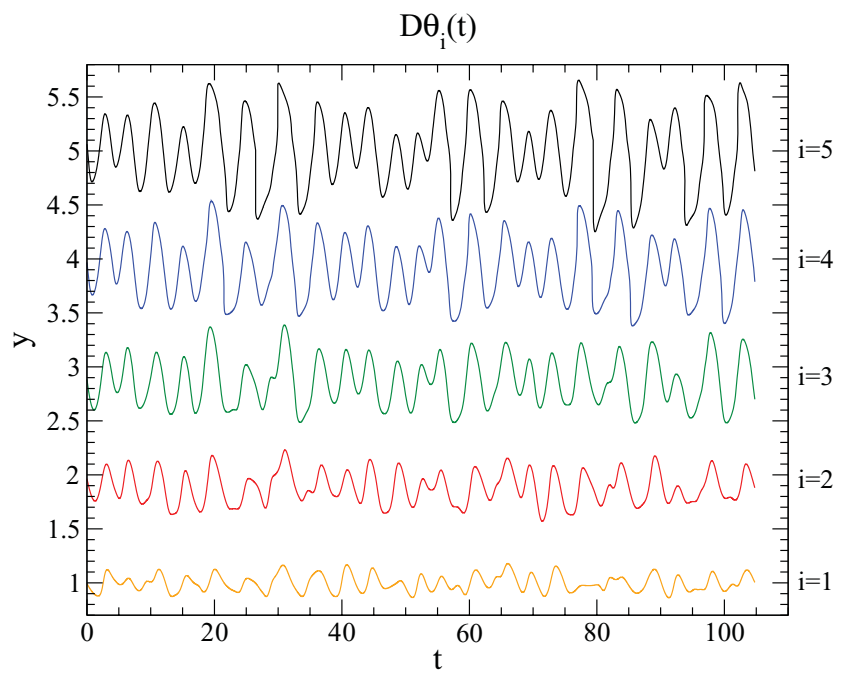

FIG. 19. Time evolutions of the five separation lines between the six first wavy rolls, $\mathrm{D} \theta_{\mathrm{i}}(\mathrm{t})(\mathrm{i}=1, \ldots, 5)$, recorded at $\mathrm{x}=170, \mathrm{y}<6$, and $\mathrm{z}=0.5$ for $\mathrm{Re}=200, \varepsilon=2$, and $\mathrm{A}_{\mathrm{exc}}=0.1$.

near the channel centre goes down and concerns cold air coming from the top plate (see Fig. 12). Therefore, at $\mathrm{z}=0.5$ and at a fixed streamwise coordinate $\mathrm{x}$ enough downstream $(\mathrm{x}=170$, for example), the spanwise temperature profiles, $\theta(\mathrm{y})$, present a local minimum near the channel centre $($ at $y \approx 5)$. This minimum marks the boundary between the two rolls at channel center. Monitoring in time the spanwise positions of this minimum for $\mathrm{x}>\mathrm{L}_{\mathrm{Vs}}$ allowed us to evaluate the spanwise displacement of the fully developed wavy rolls. The time signal recording the positions of this minimum around $\mathrm{y}=5$ at $\mathrm{z}=0.5$ and $\mathrm{x}=170$ is designated by $\mathrm{D} \theta_{5}(\mathrm{t})$. It is plotted in Fig. 19 (black curves around $y=5$ ). Similarly, it is also possible to follow the separation lines between all the successive roll pairs by recording the local minima and maxima of $\theta(\mathrm{y})$. Figure 19 presents the successive positions of $\mathrm{D} \theta_{\mathrm{i}}(\mathrm{t})(\mathrm{i}=1, \ldots, 5)$ of the five boundaries between the six first wavy rolls for $0 \leq \mathrm{y}<6$. It shows that the closer to the vertical walls the rolls are, the smaller the spanwise displacement magnitude is. The spanwise oscillation amplitudes of fully established wavy rolls can be measured from the distance between one peak and the following valley in $\mathrm{D} \theta_{5}(\mathrm{t})$. As $\mathrm{D} \theta_{5}(\mathrm{t})$ is recorded during a time period equal to 200 , about 90 amplitudes are measured in each signal. The corresponding mean values ( $\left.\mathrm{D} \theta_{\text {mean }}\right)$, maximum values $\left(\mathrm{D} \theta_{\max }\right)$, and standard deviations $\left(\mathrm{D} \theta_{\mathrm{sd}}\right)$ are presented in Fig. 20 for the four $\mathrm{A}_{\mathrm{exc}}$ investigated. Figure 20 shows that all these statistics are nearly constant except $\mathrm{D} \theta_{\text {mean }}$ that decreases at $\mathrm{A}_{\mathrm{exc}}=2$.

In summary, apart the wavy roll growth lengths, $\mathrm{L}_{V_{s}}$ and $\mathrm{L}_{V_{\mathrm{s}} / 2}$, and the total averaged power $\mathrm{P}_{\mathrm{av}}\left(\mathrm{v}_{\mathrm{fd}}(\mathrm{t})\right)$ of the $\mathrm{v}(\mathrm{t})$ Fourier spectra for $\mathrm{A}_{\mathrm{exc}}=2$, the inlet excitation magnitude, $\mathrm{A}_{\mathrm{exc}}$, influences slightly on the characteristics of the fully developed wavy rolls. It is therefore possible to analyze the main characteristics of fully developed wavy rolls as a function of Re and $\varepsilon$ by fixing $\mathrm{A}_{\mathrm{exc}}$, which will be done in subsection V E.

\section{E. Influence of Reynolds and Rayleigh numbers on wavy rolls}

The influence of $\operatorname{Re}$ and $\varepsilon$ on the characteristics of wavy roll flows is studied now by using $\mathrm{A}_{\mathrm{exc}}=0.1$ in order to avoid strong nonlinear effects observed with $\mathrm{A}_{\mathrm{exc}}>0.5$. Figures 21 and 22 depict the frequency, $\mathrm{f}^{\circ}$, wave number, $\mathrm{k}_{\mathrm{x}}{ }^{\circ}$, and phase velocity, $\mathrm{c}^{\circ}$, of the most amplified mode of wavy rolls with respect to $\varepsilon$ for $\operatorname{Re}=100,150$, and 200. Results at $\varepsilon=0$ correspond to the linear results given in Table I and those at $\varepsilon>0$ to the nonlinear results. $\mathrm{f}^{\circ}$ and $\mathrm{k}_{\mathrm{x}}{ }^{\circ}$ strongly increase with $\varepsilon$ as long as $\varepsilon \leq 2$ (i.e., $\mathrm{Ra} \leq 3 \mathrm{Ra}^{*}$ ) and they stabilize or decrease a little beyond. This shows that the linear stability results ( $f *$ and $\mathrm{k}_{\mathrm{x}} *$ ) cannot be used to characterize strongly nonlinear flows with wavy rolls. Figures 21 and 22 also display the characteristics of the modes with the maximum space 


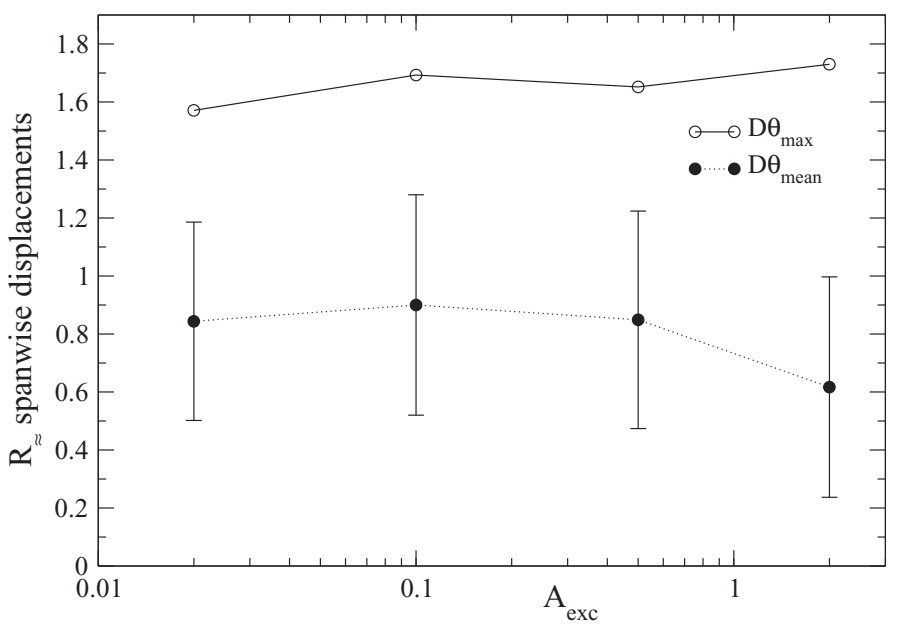

FIG. 20. Mean and maximum spanwise displacements of fully established wavy rolls with respect to $A_{\text {exc }}$, for the four flows of Fig. 12, computed from $\mathrm{D} \theta_{5}(\mathrm{t})$ displayed in Fig. 19. The vertical error bars placed on each side of the mean displacements, $\mathrm{D} \theta_{\text {mean }}$, are equal to the standard deviations, $\mathrm{D} \theta_{\mathrm{sd}}$, of $\mathrm{D} \theta_{5}(\mathrm{t})$.

growth rate measured by Pabiou et al. ${ }^{9}$ in experiments in which harmonic excitations are imposed at channel inlet. Despite of the difference between the excitation types and the uncertainties of the results, agreement between numerical and experimental results can be considered good. One can see that $\mathrm{f}^{\circ}$ and $\mathrm{k}_{\mathrm{x}}{ }^{\circ}$ also increase with $\varepsilon$ in the experiments (see the two points at $\mathrm{Re}=120$ ), but they are almost independent of $\operatorname{Re}$ in the experiments for $\operatorname{Re} \leq 174$ (see the three points at $\varepsilon \approx 1$ ), while this is not the case for the numerical simulations when Re increases from 150 to 200 . Concerning the phase velocity, it remains almost constant whatever Re and $\varepsilon$ are: $\mathrm{c}^{*} \approx 1.1$ at the linear threshold, $\mathrm{c}^{\circ}=1.1 \pm 0.08$ in the experiments ${ }^{9}$ and $\mathrm{c}^{\circ}=1.09-1.20$ in the nonlinear numerical simulations performed for different $\operatorname{Re}$ and $\varepsilon$.

It has been shown in Fig. 9 and Sec. V C that the averaged Nusselt number $\overline{\mathrm{Nu}}_{\mathrm{fd}}$ for established wavy rolls is smaller than $\overline{\mathrm{Nu}}_{\mathrm{fd}}$ of longitudinal rolls due to the mixing and the temperature homogenization operated by the spanwise oscillations of wavy rolls. But for $\operatorname{Re}=100$ and $\varepsilon=2$ and 3 (cases 2 and 3 in Table II) $\overline{\mathrm{Nu}}_{\mathrm{fd}}$ is nearly equal to the values obtained for the longitudinal rolls. This is due to the very small spanwise oscillations in the two cases. Figure 23 presents the

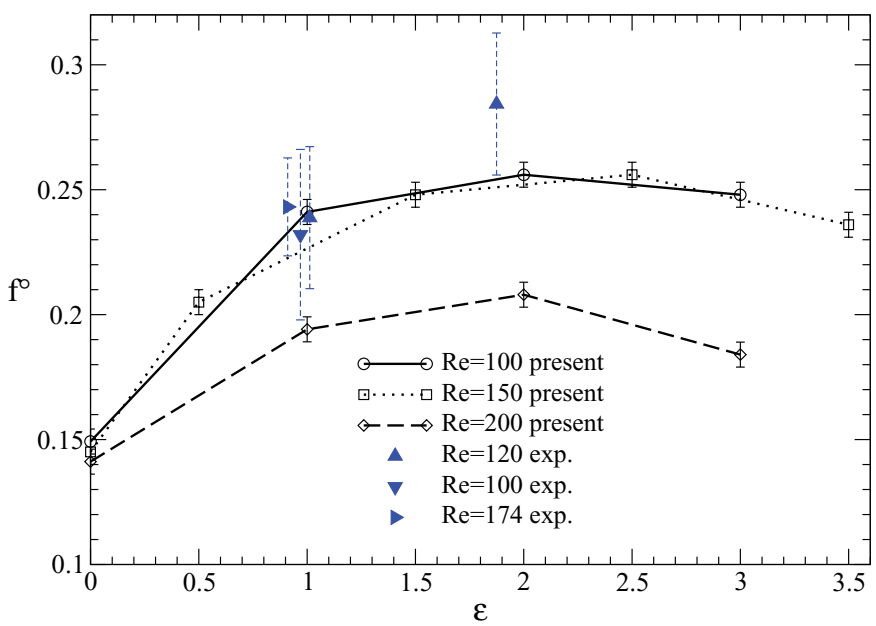

FIG. 21. Frequency, $\mathrm{f}^{\circ}$, of the most amplified modes of wavy rolls with respect to Re and $\varepsilon$ at $\mathrm{A}_{\mathrm{exc}}=0.1$. Comparison with the experiments. ${ }^{9}$ 


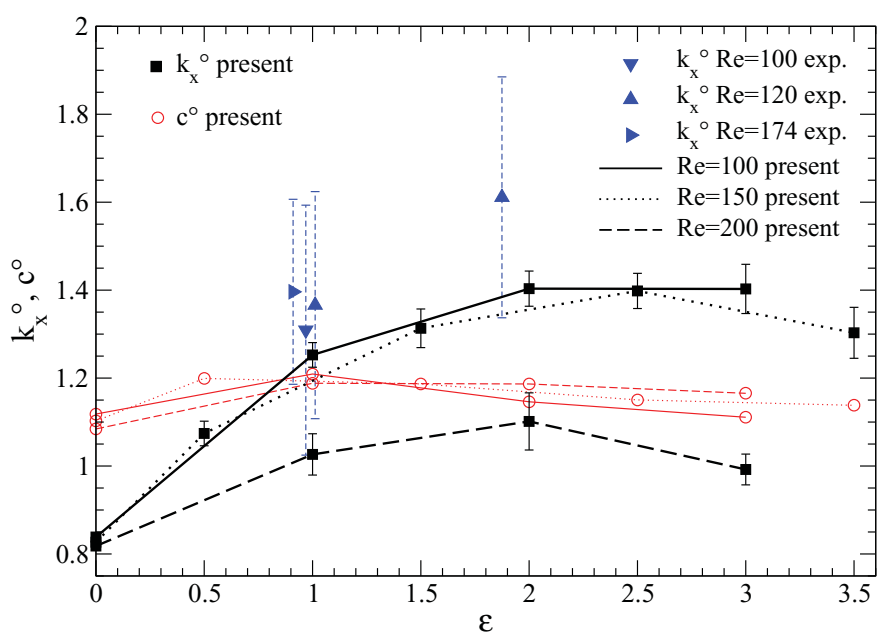

FIG. 22. Wave number, $\mathrm{k}_{\mathrm{x}}{ }^{\circ}$, and phase velocity, $\mathrm{c}^{\circ}$ (red lines with circles), of the most amplified modes of wavy rolls with respect to $\mathrm{Re}$ and $\varepsilon$ at $\mathrm{A}_{\mathrm{exc}}=0.1$. Comparison with the experiments. ${ }^{9}$

mean and maximum magnitude and the standard deviation of the wavy roll spanwise displacement computed from $\mathrm{D} \theta_{5}(\mathrm{t})$. For $\mathrm{Re}=100, \mathrm{D} \theta_{\text {mean }}$, and $\mathrm{D} \theta_{\max }$ decrease with $\varepsilon$ and they are quite small for $\varepsilon=2$ and 3. This can be explained by the fact that cases 2 and 3 are located close to the marginal stability curves $\mathrm{Ra} \approx *(\mathrm{Re})$ and $\mathrm{Ra}_{\mathrm{osc}} *(\mathrm{Re})$, displayed in Fig. 1, separating longitudinal rolls from wavy and oscillating rolls. Furthermore, these stability curves, computed in Ref. 10 for B $\rightarrow \infty$, should be slightly shifted for $B=10$. On the other hand, for $\mathrm{Re}=150$ and 200 , the mean and maximum magnitudes of the wavy roll spanwise displacement increase with $\varepsilon$ as long as $\varepsilon \leq 2$ and they increase with $\operatorname{Re}$ for $\varepsilon>2$.

The growth lengths are also modified for the cases close to the stability curves $\mathrm{Ra} \approx *(\mathrm{Re})$ and $\operatorname{Ra}_{\mathrm{osc}} *(\mathrm{Re})$. The evolution of the longitudinal and wavy roll growth lengths $\mathrm{L}_{\mathrm{R} / /}\left[\mathrm{w}_{\min }(\mathrm{y}=5\right.$; $\mathrm{z}=0.5)], \mathrm{L}_{\mathrm{Vs} / 2}$ and $\mathrm{L}_{\mathrm{Vs}}$ with respect to $\mathrm{Re}$ and $\varepsilon$ are presented in Fig. $24 . \mathrm{L}_{\mathrm{Vs}}$ and $\mathrm{L}_{\mathrm{Vs} / 2}$ are nearly independent of $\operatorname{Re}$ except for $\operatorname{Re}=100$ at $\varepsilon=2$ and 3 and, to a lesser degree, $L_{V s}$ at $\operatorname{Re}=200$ and $\varepsilon=3$. Leaving cases 2 and 3 at $\operatorname{Re}=100$, the following correlation is established for the growth

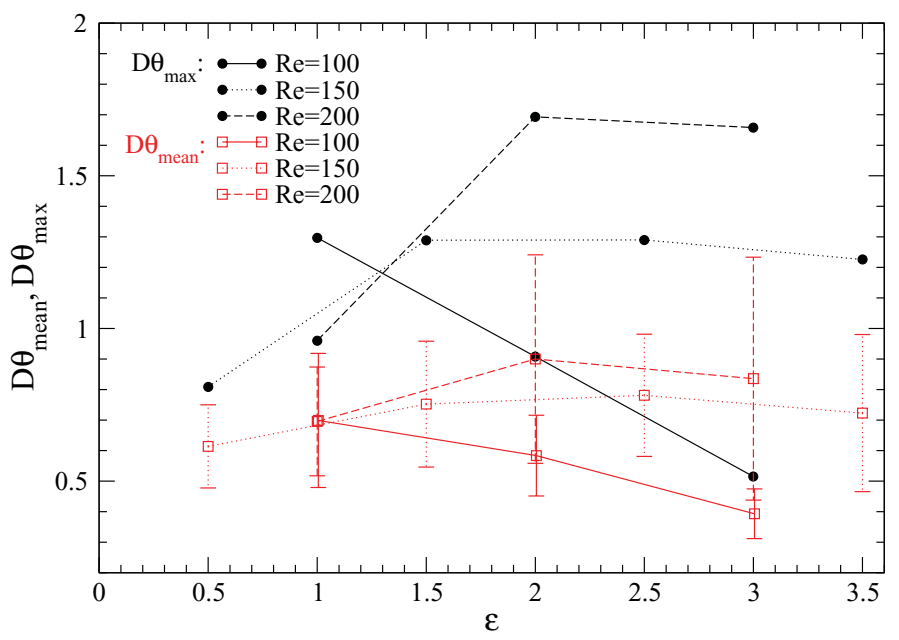

FIG. 23. Mean ( $\left.\mathrm{D} \theta_{\text {mean }}\right)$ and maximum $\left(\mathrm{D} \theta_{\max }\right)$ spanwise displacements of fully established wavy rolls, computed from $\mathrm{D} \theta_{5}(\mathrm{t})$, with respect to $\varepsilon$, for $\mathrm{Re}=100,150$, and 200 . The vertical error bars placed on each side of $\mathrm{D} \theta_{\text {mean }}$ are equal to the standard deviation, $\mathrm{D} \theta_{\mathrm{sd}}$, as in Fig. 20. 


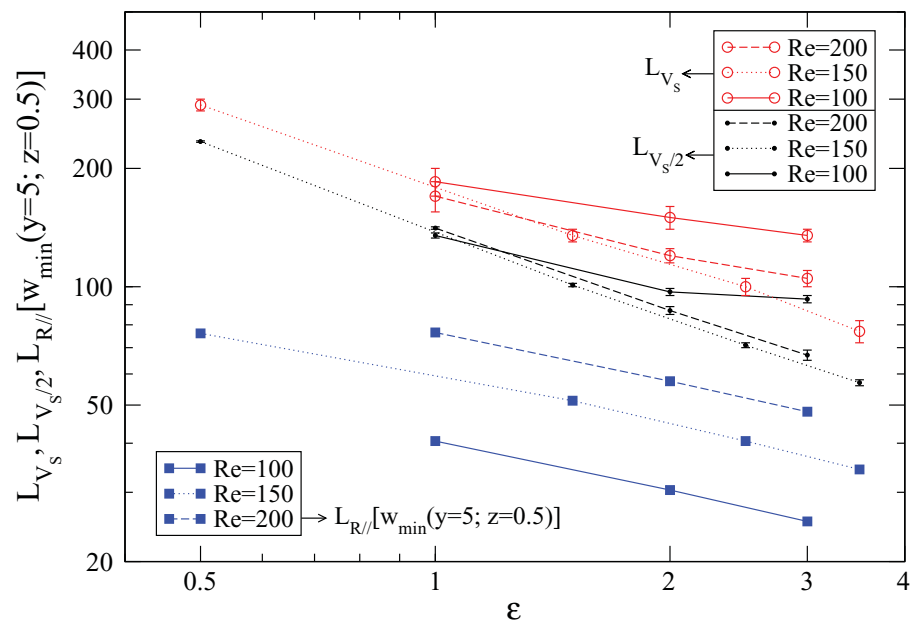

FIG. 24. Growth lengths $\mathrm{L}_{\mathrm{R} / /}\left[\mathrm{w}_{\min }(\mathrm{y}=5 ; \mathrm{z}=0.5)\right]$ of longitudinal rolls and $\mathrm{L}_{\mathrm{V}_{\mathrm{s}} / 2}$ and $\mathrm{L}_{\mathrm{V}_{\mathrm{s}}}$ of wavy rolls with respect to Re and $\varepsilon$ for $\mathrm{A}_{\mathrm{exc}}=0.1$.

length $\mathrm{L}_{\mathrm{V} / 2}$ within a $3 \%$ relative error:

$$
\mathrm{L}_{\mathrm{V} / 2}=85.03 \mathrm{Re}^{0.009} \varepsilon^{-0.719} .
$$

\section{USE OF WAVY ROLLS TO MAKE MORE UNIFORM DEPOSITIONS IN CVD REACTORS}

The analysis of Figs. 23 and 24 can also be done from the viewpoint of CVD applications. It is well known that the longitudinal thermoconvective rolls which can develop in the rectangular atmospheric pressure CVD reactors make nonuniform vapor deposition in shape of longitudinal parallel ridges on the heated substrate. It has also been shown in Ref. 3 that the unsteady wavy rolls could be used to get more uniform vapor deposits. Indeed, due to the spanwise oscillations of wavy rolls, more uniform time averaged heat and mass transfer are obtained and, therefore, more uniform films and coatings are deposited on the heated substrate. These deposits are more uniform in the presence of wavy rolls when the following three conditions are satisfied: the reactor spanwise aspect ratio must be large enough $(B \geq 10)$ to reduce the vertical wall influence that tends to decrease the magnitude of spanwise oscillations and the heat and mass transfer homogenization near the walls; the growth length of wavy rolls must be shorter than the reactor streamwise aspect ratio $\left(\mathrm{L}_{\mathrm{Vs}}<50-80\right)$ and the magnitude of the wavy roll spanwise oscillations must be large (the total spanwise displacement must be larger than about 1.5H). It has been shown in Fig. 17 that a larger magnitude of the excitation introduced at channel inlet induces shorter growth lengths $\mathrm{L}_{\mathrm{Vs}}$ and $\mathrm{L}_{\mathrm{V}_{\mathrm{s}} / 2}$. Even for $\mathrm{A}_{\mathrm{exc}}$ equal to $10 \%$ of the channel mean velocity, one can see in Fig. 24 that $\mathrm{L}_{\mathrm{Vs}}<80$ can be reached at $\operatorname{Re}=150$ and $\varepsilon=3.5$. Much smaller growth lengths can, therefore, be envisaged at higher $\mathrm{A}_{\mathrm{exc}}$ values for similar $\mathrm{Re}$ and $\varepsilon$ values.

As far as the wavy roll spanwise displacement is concerned, Fig. 23 shows that larger displacements are obtained for $\varepsilon \geq 1.5$ and $\operatorname{Re} \geq 150$. In this parameter range, mean displacements are equal to about $0.8 \mathrm{H}$ with a standard deviation of about $\pm 0.3 \mathrm{H}$ and maximum displacements vary between $1.2 \mathrm{H}$ at $\mathrm{Re}=150$ and $1.7 \mathrm{H}$ at $\mathrm{Re}=200$. In the present study, the random excitations used at the channel inlet amplify different modes. Their nonlinear interaction most probably increases the flow dissipation level and decreases the spanwise displacement magnitude comparing for instance with a case using a harmonic excitation at frequency $\mathrm{f}^{\circ}$. One can think that, in a real situation, if a sinusoidal perturbation is used at the channel inlet to excite the most amplified mode $\mathrm{f}^{\circ}$, flow dissipation level will be decreased and wavy rolls with more amplified spanwise displacements will develop in the reactor. Favorable conditions for CVD reactors can thus be achieved. 


\section{CONCLUSIONS}

This paper presents a bibliographical review and an overview of the primary and secondary convective and absolute instabilities of $\mathrm{PRB}$ air flows at $\mathrm{Pr}=0.7$ in large aspect ratio channels. Then it focuses on the characterization of longitudinal and wavy thermoconvective rolls at $100 \leq \mathrm{Re}$ $\leq 300,3000 \leq \mathrm{Ra} \leq 15000$, and $\mathrm{B}=\mathrm{W} / \mathrm{H}=10$.

As far as longitudinal roll pattern is concerned, two aspects are developed. First, the definitions usually used to measure the growth lengths of longitudinal rolls are shown to be complicated to use and about $30 \%$ shorter than the length necessary for the full development of longitudinal rolls. It is shown that the latter length should instead be computed from the profiles of the vertical velocity components along the channel axis (or that of the wall Nusselt number) because it presents an easily measurable local extremum just upstream the fully developed zone. Second, it is shown that averaged wall Nusselt number in the fully developed zone, $\overline{\mathrm{Nu}}_{\mathrm{fd}}$, computed in some numerical studies at $\mathrm{Re}$ $<100$ and $\mathrm{Ra}>8000$ is larger than the experimental ones, because longitudinal rolls remain steady in these numerical simulations, whereas they bifurcate towards an oscillating roll pattern in the experiments. In a general way, at the same $\mathrm{Re}$ and $\mathrm{Ra}$ values, $\overline{\mathrm{Nu}}_{\mathrm{fd}}$ in the presence of oscillating or wavy thermoconvective rolls is smaller than $\overline{\mathrm{Nu}}_{\mathrm{fd}}$ in the presence of steady longitudinal rolls.

Linear stability analysis of longitudinal rolls vis-à-vis wavy rolls has shown that the marginal stability curve, $\mathrm{Ra} \approx *(\mathrm{Re})$, for wavy roll appearance at $\mathrm{B}=10$ is $1.5-1.8$ times higher than the value obtained by Clever and Busse ${ }^{10}$ for $\mathrm{B} \rightarrow \infty$. Furthermore, the critical frequency, $\mathrm{f}^{*}$, and wave number, $\mathrm{k}_{\mathrm{x}}$ *, of wavy rolls at the linear stability threshold are nearly twice smaller than the values $\mathrm{f}^{\circ}$ and $\mathrm{k}_{\mathrm{x}}{ }^{\circ}$ of the most amplified nonlinear mode at $\varepsilon=2(\mathrm{Ra}=3 \mathrm{Ra} \approx *)$ obtained with a white noise at channel inlet.

Nonlinear numerical simulations with a permanent random excitation imposed on the transverse velocity components at channel inlet have permitted to characterize the wavy roll flows for $100<\mathrm{Re}<200,4500<\mathrm{Ra}<15000(0.5 \leq \varepsilon=(\mathrm{Ra}-\mathrm{Ra} \approx *) / \mathrm{Ra} \approx * \leq 3.5), \mathrm{B}=10$ and an amplitude of the inlet excitation, $A_{\text {exc }}$, varying between $2 \%$ and $200 \%$ of the mean streamwise velocity. This characterization was possible because, if the wavy rolls are a convective instability of the longitudinal rolls, they also seem to be absolutely stable vis-à-vis external excitations (if the excitation amplitude $\mathrm{A}_{\mathrm{exc}}$ is not too large) since they maintain in the whole channel, even for very large streamwise aspect ratios $(\mathrm{A}=\mathrm{L} / \mathrm{H}=350)$.

Thus the growth length, $\mathrm{L}_{\mathrm{V} / 2}$, of the wavy rolls is shown to linearly decrease with $\log \left(\mathrm{A}_{\mathrm{exc}}\right)$ and $\varepsilon^{-0.72}$. The frequency, $\mathrm{f}^{\circ}$, and the wave number, $\mathrm{k}_{\mathrm{x}}{ }^{\circ}$, of the most amplified mode, the wall averaged Nusselt number, $\overline{\mathrm{Nu}}_{\mathrm{fd}}$, and the magnitude of the spanwise displacements of the wavy rolls in the fully developed zone are shown to be independent of $\mathrm{A}_{\mathrm{exc}}$, but to increase a lot with $\varepsilon$ increasing when $\varepsilon \leq 2$. However, all these wavy roll characteristics nearly no more vary with $\varepsilon$ for $\varepsilon>2$ (i.e., for $\left.\mathrm{Ra}>3 \mathrm{Ra} \approx \approx^{*}\right)$, except the spanwise displacements at $\mathrm{Re}=100$ that decrease when $\varepsilon$ increases. The dependence with Re is more complicated. We just remind here that the magnitude of the wavy roll spanwise oscillations increase a lot when Re increases (if $\varepsilon>1$ ) and can reach $1.7 \mathrm{H}$. As for the phase velocity, $\mathrm{c}^{\circ}$, of the wavy rolls, it is equal to $1.15 \pm 0.06$ whatever the studied parameters. Correlation laws as a function of $\mathrm{Re}, \varepsilon$ and $\mathrm{A}_{\mathrm{exc}}$ have been proposed for most of the studied characteristics.

The present numerical simulations have been shown to be in good agreement with the few experimental results about the wavy rolls obtained by Pabiou et al. ${ }^{9}$ In particular, the most amplified mode of the numerical simulations is very similar to the mode with the maximum space growth rate in the experiments in which harmonic excitations are imposed at channel inlet.

Finally, the wavy roll characteristics are shown to be potentially interesting to better homogenize the vapor depositions in the horizontal rectangular CVD reactors used to make thin coatings on heated substrates from gaseous components. Indeed, as the spanwise displacements of the wavy rolls can be large $(>1.5 \mathrm{H})$ and their growth length can be enough short (most probably $<50 \mathrm{H}$ ), these thermoconvective rolls could be used to obtain time averaged more uniform thin coatings in this CVD reactor type.

It has been mentioned that, due to the random excitation at inlet, the nonlinear interaction between the different amplified wavy roll modes most probably generates a high dissipation level and the decreasing of the spanwise displacement magnitude comparing with a real case simply using 
an inlet sinusoidal excitation at the most amplified frequency $\mathrm{f}^{\circ}$ for instance. To check this statement, a design of experiments could be used to determine the most appropriate parameters simultaneously enabling to get the shortest growth length and the largest spanwise displacement of the wavy rolls, in PRB flows excited with sinusoidal excitations. This design of experiments would then depend on four factors ( $\mathrm{Re}, \varepsilon$ and the magnitude $\mathrm{A}_{\mathrm{exc}}$ and frequency $\mathrm{f}_{\mathrm{exc}}$ of the inlet harmonic excitation) and should use a quadratic response surface model, ${ }^{33}$ so that the conditions in the CVD reactors are optimized.

\section{ACKNOWLEDGMENTS}

The authors acknowledge Sophie Mergui (FAST Laboratory, Orsay, France) for providing many helpful suggestions. This work was granted access to the HPC resources of IDRIS under the allocations 2009-1474, 2010-1474, and 2011-1474 made by GENCI (Grand Equipement National de Calcul Intensif).

${ }^{1}$ X. Nicolas, "Bibliographical review on the Poiseuille-Rayleigh-Bénard flows: The mixed convection flows in horizontal rectangular ducts heated from below,” Int. J. Thermal Sc. 41, 961 (2002).

${ }^{2}$ R. L. Mahajan, "Transport phenomena in chemical vapor deposition systems," Adv. Heat Transfer 28, 339 (1996).

${ }^{3}$ X. Nicolas, A. Benzaoui, and S. Xin, "Numerical simulation of thermo-convective flows and more uniform depositions in a cold wall rectangular APCVD reactor," J. Cryst. Growth 310, 174 (2008).

${ }^{4} \mathrm{Q}$. Wang and Y. Jaluria, "Instability and heat transfer in mixed-convection flow in a horizontal rectangular duct with discrete heat sources," Numer. Heat Transfer, Part A 42, 445 (2002).

${ }^{5}$ H. W. Müller, M. Lücke, and M. Kamps, “Convective patterns in horizontal flow,” Europhys. Lett. 10, 451 (1989).

${ }^{6}$ H. W. Müller, M. Lücke, and M. Kamps, “Transversal convection patterns in horizontal shear flow," Phys. Rev. A 45, 3714 (1992).

${ }^{7}$ P. Carrière and P. A. Monkewitz, "Convective versus absolute instability in mixed Rayleigh-Bénard-Poiseuille convection," J. Fluid Mech. 384, 243 (1999).

${ }^{8}$ H. Pabiou, X. Nicolas, S. Xin, and S. Mergui, “Observations d'une instabilité convective apparaissant sous la forme de rouleaux sinueux dans un écoulement de Poiseuille-Rayleigh-Bénard,” Méca. et Industries 4, 537 (2003).

${ }^{9}$ H. Pabiou, S. Mergui, and C. Bénard, "Wavy secondary instability of longitudinal rolls in Rayleigh-Bénard-Poiseuille flows," J. Fluid Mech. 542, 175 (2005).

${ }^{10}$ R. M. Clever and F. H. Busse, "Instabilities of longitudinal rolls in the presence of Poiseuille flow," J. Fluid Mech. 229, 517 (1991).

${ }^{11}$ M. Lücke and A. Szprynger, "Noise sustained pattern growth: Bulk versus boundary effects," Phys. Rev. E 55, 5509 (1997).

12 D. Jung, M. Lücke, and A. Szprynger, "Influence of inlet and bulk noise on Rayleigh-Bénard convection with lateral flow," Phys. Rev. E 63, 056301 (2001).

${ }^{13}$ R. J. Deissler, "Spatially growing waves, intermittency and convective chaos in an open-flow system," Physica D 25,233 (1987).

${ }^{14}$ R. J. Deissler, "External noise and the origin and dynamics of structure in convectively unstable systems," J. Stat. Phys. 54, 1459 (1989)

${ }^{15}$ S. Mergui, X. Nicolas, and S. Hirata, "Sidewall and thermal boundary condition effect on the evolution of longitudinal rolls in Rayleigh-Bénard-Poiseuille convection," Phys. Fluids 23, 084101 (2011).

${ }^{16} \mathrm{~S}$. Xin, X. Nicolas, and P. Le Quéré, "Stability analyses of longitudinal rolls of Poiseuille-Rayleigh-Bénard flows in air-filled channels of finite transversal extension," Numer. Heat Transfer, Part A 50, 467 (2006).

${ }^{17}$ X. Nicolas, J.-M. Luijkx, and J.-K. Platten, "Linear stability of mixed convection flows in horizontal rectangular channels of finite transversal extension heated from below," Int. J. Heat Mass Transfer 43, 589 (2000).

${ }^{18}$ X. Nicolas, A. Mojtabi, and J.-K. Platten, "Two-dimensional numerical analysis of the Poiseuille-Bénard flow in a rectangular channel heated from below," Phys. Fluids 9, 337 (1997).

${ }^{19}$ M. T. Ouazzani, J. P. Caltagirone, G. Meyer, and A. Mojtabi, "Etude numérique et expérimentale de la convection mixte entre deux plans horizontaux à températures différentes,” Int. J. Heat Mass Transfer 32, 261 (1989).

${ }^{20}$ C. H. Yu, M. Y. Chang, and T. F. Lin, "Structures of moving transverse and mixed rolls in mixed convection of air in a horizontal plane channel,” Int. J. Heat Mass Transfer 40, 333 (1997).

${ }^{21}$ K. C. Chiu and F. Rosenberger, "Mixed convection between horizontal plates-I. Entrance effects," Int. J. Heat Mass Transfer 30, 1645 (1987).

${ }^{22}$ Y. Kato and K. Fujimura, Theoretical and Applied Mechanics, Vol. 50, pp. 327-333 (Proceedings of the 50th Japan National Congress on Theoretical and Applied Mechanics, 2001, ed. E. Watanabe). JOI is : JST.JSTAGE/nctam/50.327

${ }^{23}$ D. Avsec, "Sur les formes ondulées des tourbillons en bandes longitudinales," CRAS 204, 167 (1937).

${ }^{24}$ S. Ostrach and Y. Kamotani, "Heat transfer augmentation in laminar fully developed channel flow by means of heating from below," J. Heat Transfer 97, 220 (1975).

${ }^{25}$ F. H. Busse and R. M. Clever, "Instabilities of convection rolls in a fluid of moderate Prandtl number," J. Fluid Mech. 91, 319 (1979).

${ }^{26}$ A. Benzaoui, "Simulation numérique des écoulements de Poiseuille-Rayleigh-Bénard - Application aux procédés de fabrication de couches minces par CVD," Ph.D. dissertation (Université de Marne la Vallée, 2006). 
${ }^{27}$ M. Y. Chang and T. F. Lin, "Experimental study of aspect ratio effects on longitudinal vortex flow in mixed convection of air in a horizontal rectangular duct," Int. J. Heat Mass Transfer 41, 719 (1998).

${ }^{28}$ C. H. Yu and T. F. Lin, "Effects of aspect ratio on vortex flow patterns in mixed convection of air through a bottom-heated horizontal rectangular duct," Numer. Heat Transfer, Part A 31, 745 (1997).

${ }^{29}$ X. Nicolas, M. Medale, S. Glockner, and S. Gounand, "Benchmark solution for a three-dimensional mixed-convection flow, Part 1: Reference solutions," Numer. Heat Transfer, Part B 60, 325 (2011).

${ }^{30}$ J. Shahda and U. Narusawa, "On pattern selection in mixed convection in rectangular ducts," Heat Mass Transfer 32, 213 (1997).

${ }^{31}$ A. Benzaoui, X. Nicolas, and S. Xin, "Efficient vectorized finite-difference method to solve the incompressible NavierStokes equations for 3-D mixed-convection flows in high-aspect-ratio channels," Numer. Heat Transfer, Part B 48, 277 (2005).

${ }^{32}$ X. Nicolas, S. Gounand, M. Medale, and S. Glockner, "Benchmark solution for a three-dimensional mixed convection flow, Part 2: Analysis of Richardson extrapolation in the presence of a singularity," Numer. Heat Transfer, Part B 60, 346 (2011).

${ }^{33}$ J. Goupy and L. Creighton, Introduction to Design of Experiments with JMP Examples, 3rd ed., SAS Press Series, SAS Institute Inc., Cary, NC, USA (SAS, 2007).

${ }^{34}$ U. Narusawa, "Numerical analysis of mixed convection at the entrance region of a rectangular duct heated from below," Int. J. Heat Mass Transfer 36, 2375 (1993).

${ }^{35}$ K. Fukui, M. Nakajima, and H. Ueda, "The longitudinal vortex and its effects on the transport processes in combined free and forced laminar convection between horizontal and inclined parallel plates,” Int. J. Heat Mass Transfer 26, 109 (1983). ${ }^{36}$ H. Pabiou, "Mise en évidence expérimentale d'une instabilité convective dans un écoulement de Poiseuille-RayleighBénard," Ph.D. dissertation (Université Paris VI, 2003).

${ }^{37}$ G. J. Hwang and K. C. Cheng, "A boundary vorticity method for finite amplitude convection in plane Poiseuille flow," in Proceedings of the 12th Midwestern Mechanics Conference, University of Notre Dame [Dev. Mech. 6, 207 (1971)]. 